\title{
Dynamic Wage and Employment Effects of Elder Parent Care
}

\author{
Meghan Skira*
}

August 16, 2013

\begin{abstract}
This paper formulates and estimates a dynamic discrete choice model of elder parent care and work to analyze how caregiving affects a woman's current and future labor force participation and wages. The model incorporates parental health changes, human capital accumulation, and job offer availability. The estimates indicate that women face low probabilities of returning to work or increasing work hours after a caregiving spell. I use the estimated model to simulate the caregiving, employment, and welfare effects of a longer unpaid work leave than currently available under the Family and Medical Leave Act, a paid leave, and a caregiver allowance.
\end{abstract}

JEL Classification: J14, J18, J22, C51

Keywords: Informal care, employment, dynamic discrete choice, structural estimation, Family and Medical Leave Act

*Department of Economics, Terry College of Business, University of Georgia, Athens, GA 30602; EMail: skira@uga.edu. I am especially grateful to Peter Gottschalk, Andrew Beauchamp and Norma Coe for their valuable comments. I would also like to thank Brent Bundick, Don Cox, Michael Darden, Devlin Hanson, Donna Gilleskie, Nadia Karamcheva, Steven Lehrer, Edward Norton, Claudia Olivetti, Geoffrey Sanzenbacher, Shannon Seitz, Courtney H. Van Houtven, Mathis Wagner, France Weaver, two anonymous referees, as well as participants at the Boston College Labor Lunch Workshop, the Boston College-Boston University Greenline Labor Economics Seminar, and the 8th iHEA World Congress for helpful comments and suggestions. I gratefully acknowledge financial support from the US Social Security Administration funded as part of the Retirement Research Consortium. All errors are mine. 


\section{Introduction}

How does caregiving for an elderly parent affect a woman's current and future labor force participation and wages? Working less to provide care clearly affects a woman's current income, but it is also clear that her future labor market opportunities can be affected. Women who spend time away from work to provide care may later struggle to find a job or return to their previous wage. In addition, caregiving often involves a significant time commitment. On average, caregivers provide 10 to 20 hours of care per week for four years (MetLife, 2009a; National Alliance for Caregiving and AARP, 2009). Thus, the decision to provide care may mean a substantial loss of current and future earning capacity. These considerations make clear the potential long-term labor market effects of caregiving and underscore the inherent forward-looking nature of caregiving and work decisions.

Understanding the short and long-term effects of caregiving on work and wages is an important policy issue given the large and growing population of disabled elderly and the prevalence of informal care provided by adult daughters, most of whom have a history of working. Currently in the United States there are 9 million men and women over the age of 65 who need help with basic personal activities, household chores, or errands. By 2020, 12 million older Americans are projected to need long-term care. ${ }^{1}$ About 70 percent of the elderly rely solely on informal care from family or friends, and about two-thirds of elder parent caregivers are women, a group which has experienced increasing labor force participation rates. In light of these trends and the fact that a typical caregiver is in her fifties or early sixties (Johnson and Wiener, 2006), still in her working years, providing care may involve a considerable loss of current and future human capital and job opportunities.

Despite the intertemporal nature of caregiving and work, the existing literature has overlooked the dynamics of these decisions. Most models are static and focus only on current foregone wages, which could underestimate the costs of caregiving. In contrast to most earlier

\footnotetext{
${ }^{1}$ US Department of Health and Human Services' National Clearinghouse for Long-Term Care: http://www.longtermcare.gov/LTC.
} 
studies, I model caregiving and work decisions in an explicitly intertemporal framework. I build and estimate a dynamic discrete choice model of caregiving and work that incorporates dynamic elements such as health changes of elderly parents, human capital accumulation, and labor market frictions. These features allow for long-term labor market effects of informal care that may arise due to foregone or lower wages and decreased job opportunities during and after a caregiving spell. By incorporating these elements in a dynamic framework, I can identify various channels through which caregiving affects a woman's labor market outcomes over the short and long-term.

I estimate the structural parameters of the model using eight waves of data from the Health and Retirement Study by efficient method of moments. The results highlight various static and dynamic labor market tradeoffs faced by caregivers. Women who begin care provision are likely to continue to do so, especially if their parent is in poor health. Thus, when a woman makes caregiving and work decisions, she not only considers the tradeoff between caregiving and work today, but also the potential long-term tradeoffs generated by the persistence in caregiving. In addition, women are more likely to provide large amounts of care when their parents are in poor health, and these intensive care providers are less likely to be working, especially full-time.

The estimates also underscore the importance of labor market frictions. Women who do not work face low probabilities of receiving job offers in the future. For example, the probability a non-working woman younger than 62 will receive a part-time (full-time) offer next period is 6 to 8 ( 8 to 10 ) percent. Thus, those who leave work to provide care may find it difficult to return. The estimates also reveal that women cannot move frictionlessly between full and part-time work. As a result, a woman may not always have the option to decrease her work hours while providing care. If she does work part-time while caregiving, she is not guaranteed to be able to move to full-time work in the future. The wage estimates show that there is a wage penalty for not working in the prior period and that part-time jobs are associated with lower wage offers. Thus, women who leave work to provide care forgo 
experience and the associated wage returns, and face a lower expected wage if they return to work. In addition, caregivers are more likely to work part-time than non-caregivers, and earn a lower wage than had they worked full-time.

I use the estimated model to calculate the cost of elder parent care, which reflects both the static and dynamic costs of care provision. The median cost of care provision for women in their mid-fifties is $\$ 164,726$ over a two-year period, about the same cost as two years of nursing home care in a private room. This estimate is about seven times larger than costs found in the previous literature, which are calculated using the replacement wage approach or current foregone wages due to caregiving. Thus, calculations that ignore forward-looking behavior and the intertemporal nature of caregiving and work decisions underestimate the cost of elder parent care.

The estimated structural parameters are then used to analyze how various government sponsored programs for elder parent care affect a woman's caregiving and work decisions. I analyze three counterfactual policy experiments: (1) A two-year unpaid work leave to provide care for a parent; (2) A two-year paid work leave; and (3) A caregiver allowance where those who provide care receive a payment that is not linked to their employment status and can be received indefinitely. The first policy experiment is a lengthier version of the Family and Medical Leave Act (FMLA) of 1993 which allows workers to take up to a 12-week unpaid leave to care for an ill family member and guarantees the worker will return to his/her job at the same wage. The second policy experiment is of particular interest as paid leaves have recently received much attention both at the national and state-level. ${ }^{2}$ The caregiver allowance experiment may inform about the labor market effects of policies similar to that of the recently suspended CLASS Act.

The results of the policy experiments show that both the unpaid and paid leaves generate

\footnotetext{
${ }^{2}$ For example, H.R. 1723 The Family Leave Insurance Act of 2009 was introduced in the $111^{\text {th }}$ Congress to provide for a paid family and medical leave insurance program. Also, the federal budget for fiscal year 2011 established a $\$ 50$ million State Paid Leave Fund within the Department of Labor to provide competitive grants to help states launch paid family leave programs similar to those already established in California and New Jersey.
} 
modest increases in intensive care provision, and encourage more work, especially full-time, among women who ever provide intensive care to a parent. On the other hand, the caregiver allowance generates substantial increases in intensive care provision, but leads to an increase in non-work among women who ever provide intensive care. A comparison of the welfare gains generated by the policies shows that over half the value of the paid leave can be achieved with the unpaid leave, and the caregiver allowance and the unpaid leave generate comparable welfare gains. The gains generated by the leaves emphasize the value of guaranteeing a caregiver can return to work, and underscore the importance of taking an intertemporal approach to modeling caregiving and work decisions.

The paper proceeds as follows. Section 2 discusses the literature. The model is presented in Section 3. Identification is discussed in Section 4. Section 5 describes the data, discusses empirical implementation, and provides descriptive statistics. Estimation is discussed in Section 6. Section 7 presents the main results, model fit, and the cost of elder parent care calculation. Section 8 discusses the counterfactual policy experiments and results. A brief conclusion is presented in Section 9.

\section{Related Literature}

This paper contributes to two strands of the literature. The first examines the relationship between elder parent care and labor market outcomes such as labor force participation, work hours, and wages. Most US and European studies find a negative relationship between female labor force participation and caregiving (Ettner, 1995; Pavalko and Artis, 1997; Heitmueller, 2007; Bolin et al., 2008; Crespo and Mira, 2010). ${ }^{3}$ However, the magnitude of this negative correlation varies across studies, ranging from an almost negligible effect to a 30 percentage point decrease in the probability of working. In addition, this negative correlation is stronger among intensive caregivers, or those with a greater commitment of caregiving time (Ettner, 1995; Carmichael and Charles, 1998; Heitmueller, 2007; Casado-Marín et al., 2011).

\footnotetext{
${ }^{3}$ Wolf and Soldo (1994) is a notable exception which finds no evidence of informal care reducing the propensity of married women to be employed.
} 
There is less consensus concerning whether caregivers who remain in the labor force reduce their work hours. Wolf and Soldo (1994), Bolin et al. (2008), and Casado-Marín et al. (2011) find little evidence of caregiving reducing work hours, while Ettner (1996), Johnson and LoSasso (2000), and Van Houtven, Coe, and Skira (2013) find female caregivers in the US reduce their work hours. In terms of wage effects, Carmichael and Charles (2003) find caregiving for more than 10 hours per week reduces current wages by 9 percent for women in the UK, and Heitmueller and Inglis (2007) find caregivers in the UK earn 3 percent less than non-caregivers with similar characteristics. Van Houtven, Coe, and Skira (2013) find caregiving leads to a 3 percent reduction in a woman's hourly wage in the US. While this literature examines several tradeoffs between caregiving and female labor supply, the tradeoffs are analyzed in isolation. In addition, these studies evaluate the effect of caregiving today on a woman's current labor market outcomes. ${ }^{4}$ This is the first paper to examine the effects of caregiving on current and future labor force participation, at the intensive and extensive margins, as well as wages in one comprehensive framework.

This paper also contributes to the literature that formulates theoretical models of caregiving and work. Almost all of the models are static time allocation models where the adult child makes caregiving and work decisions at a single point in time and the only cost of caregiving is current foregone wages (see for example, Börsch-Supan et al., 1992; Johnson and LoSasso, 2000; Crespo and Mira, 2010; Knoef and Kooreman, 2011). There is no forwardlooking behavior, no parental health dynamics, and no long-term costs of caregiving. Fevang et al. (2012) is the only study which provides a theoretical model of caregiving and work with multiple periods. In that model, however, perfect foresight is assumed. In addition, the adult child can freely adjust her work hours over the three periods, and the wage is assumed to be constant over all periods.

I expand upon the literature by modeling caregiving and work decisions in an intertempo-

\footnotetext{
${ }^{4}$ Heitmueller et al. (2010) and Moscarola (2010) allow last year's caregiving decision to affect current labor force participation but do not allow for direct contemporaneous effects of caregiving on employment. Spiess and Schneider (2003) find recently terminating care provision is insignificantly related to changes in work hours in Europe.
} 
ral framework which includes a forward-looking adult daughter, parental health uncertainty, human capital accumulation, and labor market frictions. The model allows informal care to have long-term labor market effects through several channels, such as foregone or lower wages over time and decreased job offers. With the exception of Knoef and Kooreman (2011), the structural parameters of the theoretical models are not estimated in the above-mentioned studies. ${ }^{5}$ By estimating the structural parameters of the model, I can simulate counterfactual policy experiments such as the work leave and caregiver allowance programs described above. No studies have attempted to analyze the impact of government sponsored elder parent care programs on the caregiving and labor supply decisions of adult children in the US or the welfare gains generated by such policies.

\section{Model}

To answer the questions posed above, I propose a one-child one-parent dynamic discrete choice model in which an adult daughter makes joint decisions about caregiving and work. ${ }^{6}$ The optimization problem, consistent with the data available for estimation, begins at a point in the middle of the daughter's lifecycle. ${ }^{7}$ At any period $t$, the daughter has up to two decisions to make. She makes an employment decision, $E=\{0, P T, F T\}$, consisting of nonemployment, part-time work, and full-time work alternatives, respectively, and a caregiving decision (given a parent is alive), $C G=\{0,1,2\}$, consisting of no caregiving, light caregiving, and intensive caregiving alternatives, respectively. ${ }^{8}$

\footnotetext{
${ }^{5}$ Knoef and Kooreman (2011) estimate the structural parameters of their static model using only children, and then use those estimates to assess the nature of interactions between siblings. Börsch-Supan et al. (1992) jointly model employment and "time spent with parents," and estimate equations based on the underlying structural model.

${ }^{6}$ I abstract from the other parent since less than 7 percent of female caregivers care for both parents simultaneously. If both parents are alive, spousal caregiving is the most prevalent form of informal care (Spillman and Pezzin, 2000). I abstract from other adult children since among families with at least one informal care provider and at least two adult children, only 14 percent include multiple caregiving adult children (Byrne et al., 2009). Modeling a dynamic sibling bargaining game is beyond the scope of this paper but is a promising avenue for future research.

${ }^{7}$ Initial conditions are those that prevail at that lifecycle point, and are addressed in Section 5.3.

${ }^{8} \mathrm{I}$ abstract from the living arrangement of the parent for model tractability, and hence do not distinguish between co-residential and non-co-residential caregiving.
} 


\subsection{Preferences}

The woman is forward-looking and at any time $t$, her objective is to maximize her expected lifetime utility, $U_{t}$, given the choice set she faces. A woman's period utility, $u_{t}$, is determined by her consumption, $C_{t}$, leisure time, $L_{t}$, and caregiving decision, $C G_{t}$. The daughter receives utility from light and intensive caregiving which varies with the health of her parent, $H_{t}^{p}{ }^{9}{ }$ In addition, there is a utility cost to initiating care which varies with the health of the parent. This captures the idea that beginning care provision may involve substantial adjustments (in the daughter's schedule, for example) and start costs. Utility from caregiving also varies with whether the woman has a sister, sis $s_{t}{ }^{10,11}$

The caregiving utility parameters are best interpreted as capturing the net utility from caregiving since they reflect both utility gains and losses from care provision. For example, the daughter could be motivated to provide care by reciprocity, responsibility norms, or altruism toward her parent which positively affect her utility. At the same time, care provision can be stressful and burdensome. ${ }^{12}$ By allowing the utility from caregiving to vary with parental health, I allow for the possibility that the stress of care provision, the degree of altruism, and feelings of reciprocity and responsibility differ with the care needs of the parent. ${ }^{13}$ Similarly, by allowing the utility from caregiving to vary with whether the woman has a sister, I allow for the possibility that feelings of responsibility differ when other sisters are potential caregivers, for utility gains from potential shared care provision, and for disutility

\footnotetext{
${ }^{9}$ Parental health is discussed in detail in Section 3.5.

${ }^{10}$ Utility from caregiving does not vary with whether the woman has a brother since the literature finds that all else equal, daughters are significantly more likely than sons to provide care (Engers and Stern, 2002; Checkovich and Stern, 2002; Byrne et al., 2009).

${ }^{11}$ I assume the utility from care provision does not vary with the parent's financial needs. McGarry (1998) finds no significant difference between more and less wealthy parents in the probability of receiving informal care from children. Brown (2007) finds no evidence that children provide care in response to their parents' financial need, but rather to their parents' care needs in a dynamic structural model of parents' retirement asset choices and family care arrangements. Furthermore, data limitations prevent direct modeling of parental assets and wealth, particularly the parent's Medicaid eligibility status.

${ }^{12}$ It is also possible that the stress of care provision adversely impacts the caregiver's health, which is not explicitly modeled here.

${ }^{13}$ In the estimation, the utility from caregiving parameters are not constrained to be positive or to follow any systematic pattern over parental health or caregiving intensity.
} 
from potential free-riding among siblings. The preference parameters reflect a combination of these utility gains and losses.

Following a number of studies in the structural retirement literature, ${ }^{14} \mathrm{I}$ allow the woman's preference for leisure to increase linearly with age. I also allow for permanent unobserved heterogeneity in preferences through differences in the utility from leisure. ${ }^{15}$ The period utility function is assumed to be linear in its arguments and is given by:

$$
u_{t}=u\left(\ln \left(C_{t}\right), \ln \left(L_{t}\right), C G_{t} ; \text { age }_{t}, H_{t}^{p}, \text { sis }_{t}, C G_{t-1}, \ell, \nu_{t, E, C G}\right) \text {, }
$$

where $\ell$ denotes the woman's unobserved type and $\nu_{t, E, C G}$ denotes time-varying unobserved utility from each choice in the model. The unobserved utility arguments, $\nu_{t, E, C G}$, are assumed to be additively separable, serially uncorrelated, and normally distributed with mean zero and covariance matrix $\Sigma_{\nu}$ to be estimated. ${ }^{16}$ The exact utility function specification is provided in Appendix A.

\subsection{Time and Budget Constraints}

The daughter's leisure, $L_{t}$, is constrained to equal the time that remains in a period given her work and caregiving choices. Caregiving is a use of time that is valued differently than leisure since a woman gets direct utility from caregiving, but the time constraint makes it clear that the direct opportunity cost of caregiving is foregone leisure time. The time constraint is given by:

$$
L_{t}=\bar{T}-h_{t}^{E}-h_{t}^{C G}
$$

\footnotetext{
${ }^{14}$ Examples include Rust et al. (2003), Gustman and Steinmeier (2005), and French and Jones (2011).

${ }^{15}$ I allow for two types, $\ell \in\{1,2\}$, who differ in permanent features unobserved to the econometrician. In addition to having different leisure preferences, the types have different wage offer intercepts as discussed in Section 3.4.

${ }^{16}$ More precisely, two covariance matrices are estimated. A $9 \times 9$ covariance matrix governs the unobserved utility from each joint caregiving and work choice for those with a parent alive. A $3 \times 3$ covariance matrix governs the unobserved utility from each work choice for women without a parent alive (since they no longer make a caregiving decision).
} 
where $\bar{T}$ is the total time available per period, $h_{t}^{E}$ denotes the hours associated with the woman's employment choice, and $h_{t}^{C G}$ denotes the hours associated with her caregiving choice.

The daughter's consumption, $C_{t}$, is constrained by the sum of her hourly wage, $w_{t}$, times hours worked, $h_{t}^{E}$, and non-labor income, $y_{t} \cdot{ }^{17}$ Non-labor income varies with the woman's education, age, marital status, and whether her parent recently passed away, and is included because the woman may receive income from other sources such as her spouse, retirement benefits, or inheritances. ${ }^{18}$ Thus, non-labor income captures the influences of spousal labor supply. The non-labor income process is estimated outside the structural model and is discussed in more detail in Appendix B. The budget constraint is given by:

$$
C_{t}=w_{t} h_{t}^{E}+y_{t}
$$

\subsection{Job Dynamics}

If a woman worked part-time in period $t-1$, she is assumed to receive a part-time offer with certainty in period $t$, and if she worked full-time in period $t-1$, she is assumed to receive a full-time offer with certainty in period $t .{ }^{19}$ If the woman was not working part-time in

\footnotetext{
${ }^{17}$ I abstract from including a savings choice directly in the model. This may be a concern if those with more savings substitute away from informal care and purchase care for their parents. However, in the data, there is no descriptive evidence of a lower probability of informal care provision for those with more liquid wealth. In addition, Byrne et al. (2009) find among families where elderly parents receive formal health care, only 9 percent of these parents receive financial contributions for this care from their children. There could be a concern that those with more wealth can afford to provide care by consuming their savings; however, there is no descriptive evidence that caregivers experience significantly different changes in assets or savings than non-caregivers. Savings is currently incorporated in the model in that the woman's initial liquid assets enter the unobserved type probabilities, which is discussed in more detail in Section 5.3. This inclusion allows for persistent differences in behavior based on wealth that operate through the permanent unobserved heterogeneity.

${ }^{18}$ In the model, caregiving decisions are not motivated by inheritances or inter-vivos transfers. Most recent studies do not support the bequest motive (Checkovich and Stern, 2002; Norton and Van Houtven, 2006; Brown, 2007). The evidence on inter-vivos transfers is mixed. McGarry and Schoeni (1997) and Brown (2006) find parents do not transfer significantly more to their caregiving children than their non-caregiving children on average, while Norton and Van Houtven (2006) find caregiving children are 11 to 16 percentage points more likely to receive an inter-vivos transfer.

${ }^{19}$ Since transitions from full-time to part-time work, and vice versa, are infrequent in the data, job holding is assumed. About 17 percent of those working part-time in period $t$ transition to full-time work the next period, and 11 percent of those working full-time in period $t$ transition to part-time work the next period.
} 
period $t-1$, either because she was not working or was working full-time, she receives a part-time offer in period $t$ with probability $\lambda^{P T}\left(\mathbf{Z}_{t}\right)$, where $\mathbf{Z}_{t}$ is a vector of the woman's characteristics. If she was not working full-time in period $t-1$, either because she was not working or was working part-time, she receives a full-time offer in period $t$ with probability $\lambda^{F T}\left(\mathbf{Z}_{t}\right)$. The offer probabilities reflect both search by the woman and contact made by the firm. The offer probabilities are given by:

$$
\lambda^{E}\left(\mathbf{Z}_{t}\right)=\frac{\exp \left[\lambda^{E} \mathbf{Z}_{t}\right]}{1+\exp \left[\lambda^{E} \mathbf{Z}_{t}\right]} \quad E \in\{P T, F T\}
$$

where

$$
\lambda^{E} \mathbf{Z}_{t}=\lambda_{0}^{E}+\lambda_{1}^{E} I\left(E_{t-1}=0\right)+\lambda_{2}^{E} I\left(a g e_{t} \geq 62\right)+\lambda_{3}^{E} I\left(e d u c_{t}=2\right)+\lambda_{4}^{E} I\left(e d u c_{t}=3\right) .
$$

The vector $\mathbf{Z}_{t}$ includes whether the woman did not work last period, $I\left(E_{t-1}=0\right)$, whether she has reached the age of $62, I\left(\right.$ age $\left._{t} \geq 62\right)$, and her education. ${ }^{20}$ The offer probabilities depend on whether the woman has reached age 62 since Social Security retirement benefits can be claimed at this age and could consequently affect search intensity. Job offer arrival rates are constant over calendar time; thus, they do not account for business cycle effects.

\subsection{Wage Offers}

If a woman receives a job offer, she also receives an hourly wage offer given by:

$$
\begin{aligned}
\ln w_{t}= & \beta_{0, \ell}+\beta_{1} \text { age }_{t}+\beta_{2} a g e_{t}^{2}+\beta_{3} \text { exper }_{t}+\beta_{4} \text { exper }_{t}^{2}+\beta_{5} I\left(\text { educ }_{t}=2\right)+ \\
& \beta_{6} I\left(\text { educt }_{t}=3\right)+\beta_{7} I\left(E_{t}=P T\right)+\beta_{8} I\left(E_{t-1}=0\right)+\epsilon_{t},
\end{aligned}
$$

where exper $_{t}$ is actual years of work experience, $I\left(e d u c_{t}=2\right)$ and $I\left(e d u c_{t}=3\right)$ are education indicators for having completed high school and at least some college, respectively, and $\epsilon_{t}$ is an i.i.d. wage unobservable which is distributed normal with mean zero and variance $\sigma_{w}^{2}$ to

\footnotetext{
${ }^{20}$ Education is discretized into three categories: (1) Less than a high school degree; (2) High school degree/GED; and (3) At least some college.
} 
be estimated. Thus, wages grow if there are substantial returns to work experience and fall if there are penalties for being out of the workforce in the previous period or for working at a part-time job. Permanent unobserved heterogeneity in wages is incorporated by allowing the offer intercept to differ by unobserved type $\ell$.

\subsection{Parental Health Transitions}

Parental health is a crucial element in the model as it provides an important channel for dynamics and helps to generate persistence in caregiving. The parent's health is assumed to be unaffected by informal care provided by the daughter. ${ }^{21}$ Thus, a woman does not provide care to change the health trajectory of her parent, but because she derives utility from caregiving which varies with the parent's health. The health of the parent takes on four discrete states: (1) Healthy; (2) Has any activities of daily living (ADL) limitations or has a memory or cognition problem; (3) Cannot be left alone for an hour or more; and (4) Death. ${ }^{22}$ Parental health is modeled as a Markov process, which helps capture the fact that a parent's need for care may be sporadic, sustained, or intensified over the course of a caregiving episode. The health transition probabilities are estimated outside the structural model with a multinomial logit specification such that

$$
\begin{array}{r}
\operatorname{Pr}\left(H_{t}^{p}=k\right)=\frac{\exp \left[\gamma_{0}^{k}+\gamma_{1}^{k} I\left(H_{t-1}^{p}=a d l\right)+\gamma_{2}^{k} I\left(H_{t-1}^{p}=\text { alone }\right)\right]}{1+\sum_{m=a d l}^{\text {death }} \exp \left[\gamma_{0}^{m}+\gamma_{1}^{m} I\left(H_{t-1}^{p}=a d l\right)+\gamma_{2}^{m} I\left(H_{t-1}^{p}=\text { alone }\right)\right]} \\
\text { for } k=\text { healthy, ADL, alone, death } .
\end{array}
$$

\footnotetext{
${ }^{21}$ In the data, informal care provision is positively correlated with poor parental health. Health transition estimates with informal care as an input imply that caregiving has no significant effect on parental health or leads to worsening parental health. Byrne et al. (2009) estimate elderly health-quality production functions and find informal care provided by children is relatively ineffective. Byrne et al. (2009) explain that informal care does not influence parental health but instead helps the parent deal with health problems or simply makes the parent happier.

${ }^{22}$ Activities of daily living include bathing, dressing, and eating. The choice of health states is motivated by the parental health information available in the HRS data. I cannot distinguish between transitory and persistent shocks within these health states.
} 
Coefficients indexed by $k=$ healthy are normalized to zero. ${ }^{23} \mathrm{I}$ allow recovery from all health states except death. ${ }^{24}$

\subsection{Dynamic Programming Problem}

A woman's objective in any period $t$ is to maximize her expected lifetime utility given by:

$$
\max _{d_{t} \in D_{t}} U_{t}=E\left[\sum_{t^{\prime}=t}^{T} \beta^{t^{\prime}-t} u_{d_{t^{\prime}}} \mid \mathbf{S}_{t}\right]
$$

where $D_{t}$ is the woman's decision set at time $t$ which consists of feasible combinations of $E_{t}$ and $C G_{t}$ that vary with whether her parent is alive and her available job offers, $d_{t}$ is a specific choice within the decision set, $u_{d_{t}}$ is the period utility from a specific choice at time $t, T$ is the terminal period of the model, ${ }^{25} \beta$ is the discount factor, and $\mathbf{S}_{t}$ is a vector of the woman's state variables. A woman's state variables include her last period's employment decision, $E_{t-1}$, her last period's caregiving decision, $C G_{t-1}$, her age, $a g e_{t}$, her years of work experience, exper ${ }_{t}$, her education, educt, her marital status, mar $_{t}$, whether she has a sister, sis $s_{t}$, her parent's realized health state at time $t$ and $t-1, H_{t}^{p}$ and $H_{t-1}^{p}$, and her type, $\ell$. In addition, utility from each choice depends on the realized wage unobservable and unobserved utility arguments, denoted by vector $\boldsymbol{\epsilon}_{t}$. The vector of state variables at time $t$ is given by:

$$
\mathbf{S}_{t}=\left\{E_{t-1}, C G_{t-1}, \text { age }_{t}, \text { exper }_{t}, \text { educt }_{t}, \text { mar }_{t}, \text { sis }_{t}, H_{t}^{p}, H_{t-1}^{p}, \ell, \boldsymbol{\epsilon}_{t}\right\}
$$

Women make decisions assuming their marital status will be the same next period, and having a sister does not change between periods. ${ }^{26}$

\footnotetext{
${ }^{23}$ Estimation of the health transitions controlling for the parent's age shows that the impact of the parent's age is trivial after conditioning on last period's health state. Given this result and the fact that it is a cumbersome state variable to track, I omit parental age from these transitions.

${ }^{24}$ In the data there is recovery to better health states, so I do not restrict the health transition matrix to be diagonal.

${ }^{25}$ The terminal period occurs at age 70 . At that time the woman cannot work, but she may make a final caregiving decision.

${ }^{26}$ Fewer than 4 percent of women in the data experience a change in marital status between periods and fewer than 2 percent experience a loss of a sister between periods.
} 
The lifetime utility maximization problem given in equation 7 can be rewritten in terms of value functions. The maximum expected value of discounted lifetime utility at time $t$ can be represented by the period $t$ value function:

$$
V_{t}\left(\mathbf{S}_{t}\right)=\max _{d_{t} \in D_{t}}\left[V_{d_{t}}\left(\mathbf{S}_{t}\right)\right]
$$

where $V_{d_{t}}\left(\mathbf{S}_{t}\right)$, the choice-specific expected lifetime value function, obeys the Bellman equation

$$
\begin{gathered}
V_{d_{t}}\left(\mathbf{S}_{t}\right)=u_{d_{t}}+\beta E\left(V_{t+1}\left(\mathbf{S}_{t+1} \mid d_{t}, \mathbf{S}_{t}\right)\right) \quad \text { if } t<T \\
V_{d_{t}}\left(\mathbf{S}_{t}\right)=u_{d_{t}} \quad \text { if } t=T .
\end{gathered}
$$

Thus, the value of any decision at time $t$ is a function of the period utility from that choice plus the discounted expected value of future behavior given the woman's choice at time $t$. The expectation is taken over the distribution of future unobserved utility from each choice and future wage unobservables as well as the parental health transition probabilities and job offer probabilities.

\subsection{Solution Method}

The dynamic programming problem is solved by backward recursion given a set of model parameters. In the last period, expected values of the optimal choice are calculated for each reachable state space $\mathbf{S}_{T}$ and each potential choice set via Monte Carlo simulation. For example, for a set of terminal period state variables $\mathbf{S}_{T}, n$ draws of the wage unobservable and unobserved utility arguments are drawn and the maximum of the choice-specific value functions is calculated and recorded for each draw. ${ }^{27}$ The average of the maximum value functions over the $n$ draws is the expected maximum value of arriving at time $T$ with that choice set available and state space $\mathbf{S}_{T}$. Moving back one period, that expected value is used to do the same calculation for period $T-1$, and this procedure is repeated until the first

\footnotetext{
${ }^{27} 175$ draws are used for the numerical integration.
} 
period is reached. This process is described in greater detail in Keane and Wolpin (1994). The expected value functions are calculated at all feasible state space points for each period $t$; thus, no interpolation is used.

\subsection{Model Summary}

The model allows for current and long-term labor market effects of caregiving in several ways. First, job offer probabilities depend on the woman's prior work decision. Thus, if a woman leaves work or decreases her work hours at some point during a caregiving episode, she may face a reduced probability of receiving offers in future periods, and hence find it difficult to return to work or increase her work hours. Second, wage offers depend on a woman's years of work experience, whether she worked last period, and whether the offer is associated with a part-time job. Thus, women who leave work while caregiving forgo returns to experience and may face lower future wage offers due to penalties for being out of the workforce. Such penalties could arise from human capital depreciation, stigmatization, or employer discrimination. In addition, if women make adjustments on the intensive margin while caregiving and transition to part-time work, they may face a lower wage offer. Third, the health transitions are modeled such that the parent's health could improve, be sustained, or deteriorate. As a result, the caregiving trajectory is uncertain and the associated work adjustments (for example to non-work or part-time work) could potentially last several periods.

\section{Identification}

Since only accepted job offers are observed, the econometrician typically cannot distinguish whether a woman's decision not to work was the result of rejecting a job offer or not receiving an offer. Furthermore, if she receives a job offer, it is typically difficult to distinguish whether rejection occurs because she has a high preference for leisure or she received a low wage offer. A variety of assumptions and model features allow for separate identification of the utility from leisure, the wage offer parameters, and the parameters of the job offer probabilities. First, identification of the wage offer parameters relies on covariation between 
accepted wages and variables that appear in the wage offer equation. Second, exclusion restrictions and functional form assumptions both help. For example, the job offer probabilities depend non-linearly on whether the woman has reached age 62 , but the utility from leisure increases linearly with age, and wage offers depend continuously on age and aged squared. Education also serves as an exclusion restriction since it shifts the job offer probabilities but does not impact the utility from leisure. In addition, the job holding assumption helps to separately identify the utility from leisure from the job offer parameters. A woman who works full-time (part-time) is assumed to have a full-time (part-time) job offer with certainty in the next period, which means when a woman moves from full or part-time work to nonwork, the econometrician knows a job was available and the expected wage offer. Thus, the utility from leisure can be identified by women transitioning from full or part-time work to non-work, since non-work was chosen over an offered wage. The offer probabilities are then separately identified by observed transitions from non-work to full or part-time work, from part to full-time work, and from full to part-time work.

The utility from caregiving parameters are separately identified from the utility from leisure in several ways. First, women who no longer have a parent alive only make work choices, thus their leisure time is only a function of their work choice, and their work decisions help to identify the utility from leisure. The assumed exogeneity of parental death allows the utility from leisure to be pinned down by this subgroup of women. Second, the utility from caregiving varies with parental health, while the utility from leisure does not. Thus, if women with parents in a certain health state are observed to caregive more than women with parents in another health state but who are otherwise similar, this would be explained by differences in the utility from caregiving over different health states, not by a lower preference for leisure. In addition, utility from caregiving varies with whether the woman has a sister or not. If women without sisters are observed to caregive more frequently than women with sisters, this again would be explained by differences in the utility from caregiving, not by a lower preference for leisure. 
Identification of the wage offer parameters can be viewed as a sample selection problem since only accepted wage offers are observed in the data. The solution to the dynamic programming problem generates the sample selection rules (i.e. generates an implicit reservation wage). The functional form, distributional, and exclusion assumptions made in the model serve the same purpose as a sample selection correction in either a two-step or full information maximum likelihood procedure (Eckstein and Wolpin, 1999). The distributional assumption is the normality of the time-varying wage unobservable, $\epsilon_{t}$, in the log wage offer function. In addition, the model generates selection into work that is driven by observables besides those of the wage offer. First, non-labor income which enters consumption varies with whether the woman has reached age 62 , her marital status, and the interaction between the two, but wage offers do not. Second, women with parents alive make a caregiving choice which depends in part on their parents' realized health state and whether they have a sister, neither of which affect the wage offer. The caregiving choice is made simultaneously with the work choice and different joint choices lead to different amounts of leisure time. The caregiving choice, however, does not have a direct impact on wage offers.

Last, permanent unobserved heterogeneity enters the model in two places. Unobserved types differ in their utility from leisure and their wage offer intercept. The idea is to allow women to differ in permanent ways unobserved to the econometrician and estimate the distribution of types to fit the persistence of their choices and observed wages. When two women who are equivalent in their observable characteristics persistently make different choices or have persistently different accepted wages, this implies they likely differ in unobservable characteristics. Thus, identification of the unobserved type proportions is achieved through across group variation in caregiving and work choices and wages. It is important to note that the inclusion of unobserved heterogeneity introduces serially correlated state variables. For example, the sum of the permanent heterogeneity component in the wage offer, $\beta_{0, \ell}$, and the i.i.d. wage unobservable, $\epsilon_{t}$, is a serially correlated state variable. Thus, women can select into caregiving and work on the basis of persistent differences in the utility from leisure and 
wage offers which are unobserved by the econometrician.

\section{$5 \quad$ Data and Empirical Implementation}

The data are drawn from the Health and Retirement Study (HRS) which is representative of the non-institutional US population born between 1931 and 1941 and their spouses. The HRS is a panel survey which provides longitudinal information on labor supply, family structure, intergenerational transfers, health, income, and assets. The baseline interviews were completed in 1992, and at that time, respondents were approximately 51 to 61 years old or were married to individuals in that age range. Follow-up interviews took place biennially. The HRS is well-suited for this study since it follows a large sample of individuals at midlife over time, many of whom have elderly parents alive. In addition, it contains information on parents of all respondents, regardless of whether the parent needs or is receiving care. Thus, I am able to examine the behavior of women who do and do not provide care.

I restrict the sample to female respondents between the ages of 42 and 70 who are from the original HRS cohort or are married to an original HRS cohort member. In addition, I restrict potential care recipients to be mothers and there are several reasons for this restriction. First, only 21 percent of the women in the HRS report having a father alive in the 1992 wave of the survey, whereas about 47 percent report having a mother alive. ${ }^{28}$ In addition, fathers are less likely to receive care than mothers (Hiedemann and Stern, 1999; Byrne et al., 2009). In the HRS data, less than one-third of the fathers ever receive care, but over one-half of the mothers receive care at some point in the sample period. ${ }^{29}$ The sample is further restricted to women who report having a mother alive the first time they are surveyed, and I use the 1994 through 2008 data for estimation of the model. The sample size is 3,094 women with 18,066 person-wave observations. ${ }^{30}$

\footnotetext{
${ }^{28}$ By the 2000 wave, only 10 percent have a father alive, whereas 30 percent have a mother alive.

${ }^{29}$ Szinovacz and Davey (2008) explain that fathers are less likely to receive care from children since wives are more likely to provide care for their husbands, and adult children are then likely to be called upon to care for their widowed mothers.

${ }^{30}$ About 625 women attrite from the sample before the 2008 survey wave, and these women are included in the estimation sample. The results are quantitatively similar when the model is estimated only on individuals who do not attrite.
} 


\subsection{Caregiving and Work Measures}

Since the HRS interviews occur biennially, a decision period in the model corresponds to two calendar years. In implementing the model, the total time available in a decision period, $\bar{T}$, is equal to 10,220 hours (14 hours per day times 730 days). Thus, time allocated to caregiving and work is assigned based on two-year decision periods.

The HRS asks respondents if they or their spouses spent 100 or more hours in the past two years helping their parents with "basic personal needs like dressing, eating, and bathing." The survey then asks who was helped and how many hours of care were separately provided by the respondent and her spouse. After 1992, respondents were also asked whether they helped with "household chores, errands, transportation, etc." Again, the survey asked who was helped and how many hours of care were separately provided by the respondent and her spouse. A woman is considered a caregiver if she has provided either type of care, and the hours she has spent providing both types of care are summed to determine whether she is a light or intensive caregiver. In the data, light caregivers are defined as women who provide less than 1,000 hours of care over a two-year period, and intensive caregivers are defined as those who provide 1,000 or more hours of care over a two-year period. In the model, those who lightly caregive are assumed to caregive for 300 hours per period, while those who intensively caregive provide 2,000 hours of care per period. ${ }^{31}$

Regarding employment status, a woman is considered to be working full-time if she works 35 or more hours per week for 36 or more weeks per year; less than this is considered parttime. In the model, those who work full-time are assumed to work 4,000 hours over the two-year period, while those who work part-time work 2,000 hours per period. ${ }^{32} \mathrm{~A}$ woman is considered to be not working if she is retired, unemployed, or reports not being in the

\footnotetext{
${ }^{31}$ The threshhold of 1,000 hours of care is chosen because it corresponds to approximately 10 hours per week if care is distributed evenly over the two years, and 10 hours is a threshhold often used in the literature for intensive caregiving (Ettner, 1995; Carmichael and Charles, 2003). Among those classified as light (intensive) caregivers the median hours of care over two years is $300(2,000)$ hours.

${ }^{32}$ In the data, the median hours worked per week by part-time (full-time) workers is 20 (40) hours. For both types of workers, the median number of weeks worked per year is 50 .
} 
labor force. Respondents are asked to report hourly wages if they are working. If the respondent reports her pay at a different frequency, the RAND HRS data files adjust the pay rate appropriately using the respondent's reported usual hours worked per week and usual weeks worked per year. The HRS also contains information on the woman's years of work experience over the lifecycle. Given a model period is two years, human capital evolves as follows:

$$
\text { exper }_{t}=\left\{\begin{array}{lll}
\text { exper }_{t-1}+2 & \text { if } & E_{t-1} \neq 0 \\
\text { exper }_{t-1} & \text { if } & E_{t-1}=0 .
\end{array}\right.
$$

\subsection{Demographic and Parental Measures}

The HRS contains information on the respondent's education, non-labor income, and family structure. In terms of family structure, in each survey wave, the woman reports her marital status, how many living siblings she has, and the gender of the siblings. The woman reports various sources of non-labor income including capital income, income from pensions and annuities, income from Social Security Disability Insurance or SSI, income from Social Security retirement, spouse, or widow benefits, income from unemployment or worker's compensation, income from other government transfers, and her spouse's labor earnings (if she is married).

The HRS reports for each respondent's parent whether he/she needs help with activities of daily living, whether he/she can be left alone for an hour or more, and in waves after 1996 whether the parent has a memory or cognition problem. The HRS does not contain information about how many or which activities of daily living the parent needs help with, but only that help is required with at least one activity. The resulting health transition 
matrix from the multinomial logit specification discussed in Section 3.5 is given below.

\begin{tabular}{lcccc}
\hline \multicolumn{5}{c}{$t$} \\
\hline$t-1$ & Healthy & ADL & Alone & Death \\
\hline Healthy & 0.784 & 0.098 & 0.048 & 0.070 \\
ADL & 0.133 & 0.425 & 0.183 & 0.258 \\
Alone & 0.139 & 0.092 & 0.396 & 0.373 \\
Death & 0 & 0 & 0 & 1 \\
\hline
\end{tabular}

\subsection{Permanent Unobserved Heterogeneity}

Women enter the HRS sample at various ages during midlife. Thus, I observe decisions beginning in the middle of the lifecycle that are conditioned on state variables that arise from prior unobserved decisions. If these "initial" conditions are not exogenous (i.e. if there is unobserved heterogeneity in preferences or constraints) direct estimation will lead to bias. ${ }^{33}$ To account for this problem, I assume the probabilities of the unobserved heterogeneity types can be represented by parametric functions of the initial state variables. If the wage unobservables and unobserved utility arguments are serially uncorrelated, the initial state variables are exogenous given type. ${ }^{34}$

The unobserved type probabilities also depend on initial conditions that are not in the woman's state space. Specifically, the type probabilities depend on the woman's initial log wage and initial discretized liquid assets. ${ }^{35}$ Liquid assets are composed of the net value of the woman's stocks, mutual funds, and investment trusts, her checking, savings, and money market accounts, and her CDs and bonds. Thus, savings enter the model through the unobserved heterogeneity, which allows women who enter the model with low or high wealth to exhibit persistent differences in caregiving and work choices as well as wages. The

\footnotetext{
33 "Initial" conditions are those that exist at the time the woman is first observed in the sample.

${ }^{34}$ Aguirregabiria and Mira (2010) provide a detailed discussion of this initial conditions problem and possible solutions, including the one described above.

${ }^{35} \mathrm{I}$ assume there is no occupational sorting in anticipation of informal care provision.
} 
specification of the type probability function is given in Appendix C.

\subsection{Descriptive Statistics}

Table 1 provides descriptive statistics for those without a mother alive and for non-caregivers, light caregivers, and intensive caregivers conditional on the woman's mother being alive. ${ }^{36}$ Light caregivers are about 2 percentage points less likely to be working than non-caregivers whereas intensive caregivers are 11 percentage points less likely to be working than noncaregivers. Both light and intensive caregivers are about 2 percentage points more likely to be working part-time than non-caregivers. While non-caregivers and light caregivers who work appear to earn about the same hourly wage, the average accepted wage for intensive caregivers is about two dollars lower. Thus, the data seems to suggest a negative relationship between caregiving and labor force participation and wages that is particularly large for intensive caregivers. Those with a mother no longer alive are older which likely explains why almost 60 percent of this group is not working.

The data indicates that caregiving frequency and intensity vary with the health of the mother. Non-caregivers are more likely to have healthy mothers than light and intensive caregivers, and light caregivers are more likely to have a mother who needs help with ADLs or has a memory or cognition problem than non-caregivers. About two-thirds of intensive caregivers have non-healthy mothers, and intensive caregivers are 16 percentage points more likely to have a mother who cannot be left alone compared to both non- and light caregivers. Table 2 shows the percentage of mothers in each health state that receive light or intensive care from their daughters. Less than 30 percent of healthy mothers receive informal care and almost all care provided is light. Over half the mothers with ADL needs or a memory problem receive care, and of those receiving care, about a quarter of them are receiving intensive care from their daughter. Caregiving for a mother who cannot be left alone for an hour or more is less common than caring for a mother with ADL needs or a memory problem which may reflect the increased caregiving burden when a parent cannot be left alone or the

\footnotetext{
${ }^{36}$ All dollar amounts are adjusted by the Consumer Price Index using 2008 as the base year.
} 
use of formal care from a home health aide or nursing home. ${ }^{37}$ However, over half the women providing care to a mother who cannot be left alone are providing intensive care.

Table 1 also indicates that non-caregivers are more likely to have a sister than light and intensive caregivers, and light caregivers are more likely to have a sister than intensive caregivers. Caregivers are slightly better educated than non-caregivers and have more years of work experience than non-caregivers, but are also slightly older on average.

\section{Estimation}

I pursue a non-likelihood-based estimation strategy, efficient method of moments (EMM), which is a type of indirect inference (see Gourieroux et al., 1993; Gallant and Tauchen, 1996). The basic idea is to fit simulated data obtained from the structural model to an auxiliary statistical model. This auxiliary statistical model can be easily estimated and must provide a complete enough statistical description of the data to be able to identify the structural parameters. Following Tartari (2006) and van der Klaauw and Wolpin (2008), the auxiliary model I use in estimation consists of a combination of approximate decision rules that link endogenous outcomes of the model and elements of the state space as well as structural relationships such as the wage equation and job offer probabilities.

Specifically, using the actual data, $y_{A}$, I estimate a set of $M_{A}$ auxiliary statistical relationships with parameters $\theta_{A}$. By construction, at the maximum likelihood estimates, $\widehat{\theta}_{A}$, the scores of the likelihood function, $L_{j}$ for $j=1, \ldots, M_{A}$, are zero. That is, $\frac{\partial L_{j}}{\partial \theta_{A, j}}=0$ where $\theta_{A, j}$ is the vector of model $j$ 's parameters. Denoting $\theta_{B}$ the parameters of the behavioral model, the idea behind EMM is to choose parameters that generate simulated data, $y_{B}\left(\theta_{B}\right)$, that

\footnotetext{
${ }^{37}$ The HRS does not contain data on formal home health care utilization by parents of respondents, but does contain information about whether the mother resides in a nursing home at the time of the survey. Formal home health care utilization is somewhat rare - approximately 13 to 14 percent of the non-institutionalized elderly rely on formal home health care (Johnson, 2007; Kaye et al., 2010), but generally in combination with informal care. In 2002, only 4 percent of the disabled elderly relied solely on paid help (Johnson, 2007). Only 8 percent of the mothers in the estimation sample reside in a nursing home, with most of them in the cannot be left alone health state. In fact, about half the mothers who cannot be left alone and do not receive informal care from their daughter reside in a nursing home. The model has been estimated including nursing home utilization as discussed later, and the results are qualitatively and quantitatively similar to those from the model presented.
} 
make the score functions as close to zero as possible. This is accomplished by minimizing the weighted squared deviations of the score functions evaluated at the simulated data. Thus, the EMM estimator of the vector of structural parameters $\theta_{B}$ is:

$$
\widehat{\theta}_{B}=\underset{\theta_{B}}{\operatorname{argmin}} \frac{\partial L}{\partial \theta_{A}}\left(y_{B}\left(\theta_{B}\right) ; \widehat{\theta}_{A}\right) \Lambda \frac{\partial L}{\partial \theta_{A}^{\prime}}\left(y_{B}\left(\theta_{B}\right) ; \widehat{\theta}_{A}\right),
$$

where $\Lambda$ is a weighting matrix and $\frac{\partial L}{\partial \theta_{A}}\left(y_{B}\left(\theta_{B}\right) ; \widehat{\theta}_{A}\right)$ is a vector collecting the scores of the likelihood functions across auxiliary models. The weighting matrix used in estimation is the identity matrix. ${ }^{38}$

EMM is used for estimating this model since the likelihood function is difficult to evaluate and the EMM approach circumvents the need to construct the choice probabilities generated by the structural model (Keane and Smith Jr., 2003). In addition there are some missing state variables in the data. Estimation via maximum likelihood requires integrating out over the distribution of these missing state variables. With the EMM approach, when a state variable is missing, missing value dummies are included in the auxiliary models and I simulate the decision of a woman using an imputed or simulated state variable for that observation.

\subsection{Auxiliary Statistical Models}

The solution of the optimization problem described is a set of decision rules in which the optimal choice made in any period is a function of the state space in that period. One class of auxiliary models used consists of parametric approximations to these decision rules. ${ }^{39}$

\footnotetext{
${ }^{38}$ The optimal weighting matrix (a block diagonal matrix where each of the diagonal matrices is the inverse of the Hessian of the auxiliary model evaluated at the actual data) is not used in this case since Keane and Smith Jr. (2003) note that estimates of the optimal weighting matrix in applications of indirect inference often do not perform well in finite samples and there were difficulties in inverting the outer product matrix. The parameter estimates remain consistent, though there is a loss of asymptotic efficiency; however, Genton and Rochetti (2003) note that the loss of efficiency is found to be limited when the identity matrix is used in indirect inference.

${ }^{39}$ For example, the utility function is unobserved to the econometrician so it is impossible to provide auxiliary models which approximate the utility function itself. However, the outcome of the utility function is a set of caregiving and work choices each period. Thus, auxiliary models that are related to these choices identify the utility parameters.
} 
Following van der Klaauw and Wolpin (2008), to keep these approximations parsimonious, I specify the decision rules as parametric functions of subgroups of state space elements. A second set of auxiliary models comprises quasi-structural relationships related to the wage equation and job offer probabilities. A third class of auxiliary models captures the correlation between initial conditions and endogenous outcomes. Appendix D contains a list of the auxiliary models used in estimation. The auxiliary models imply 497 score functions which are used to identify 68 structural parameters. ${ }^{40}$ The structural parameters being estimated include the parameters of the utility function, job offer probabilities, wage offers, unobserved type probabilities as well as the covariance matrix of the unobserved utility from each choice and the variance of the wage unobservable.

\subsection{Simulating Data for Estimation}

I perform path simulations as follows. At a given set of structural parameters, having solved the optimization problem conditional on those parameters, I simulate one-step-ahead decisions. That is, given the state variables of a woman in a given period, I simulate her decisions by drawing a vector of the disturbances and choosing the alternative with the highest value function. The permanent unobserved heterogeneity is incorporated as follows. The probability that a simulated individual is a given type depends on her initial state variables. Given that probability, each simulated observation is assigned a particular type by drawing randomly from the type probability function. The score functions from the auxiliary models are evaluated using the simulated decisions and the criterion function is calculated. ${ }^{41}$ I iterate on the parameters using the Nelder-Mead simplex method until the criterion function is minimized.

\footnotetext{
${ }^{40}$ Estimates of the auxiliary parameters are not reported but are available upon request.

${ }^{41}$ For the purpose of calculating the score function, I perform 60 simulations for each sample observation and average that observation's score functions over the simulations.
} 


\section{Results}

\subsection{Parameter Estimates}

Parameter estimates and standard errors are provided in Table 3. The model allows for two types of women who differ in their utility from leisure and wage offer intercept. The estimated distribution of types is 42 percent type 1 and 58 percent type 2, with type 2 women having a higher wage offer intercept and deriving more utility from leisure than type 1 women. ${ }^{42}$ A number of estimates are worth highlighting and make clear the static and dynamic labor market tradeoffs faced by caregivers. First, the estimates suggest initiating care provision is costly regardless of the mother's health. In addition, utility from providing care is greater (or less negative) when mothers are not healthy, and in particular when they have ADL needs or a memory or cognition problem. ${ }^{43}$ Thus, those who start caregiving are likely to continue to do so, especially if their mother is no longer healthy, since they have already incurred the initiation cost. As a result, the model generates persistence in caregiving, an important dynamic channel. A woman considers that if she provides care today, she will likely do so again next period, and she will make a work decision today which accounts for this persistence in caregiving and the long-term tradeoffs it generates.

The estimates of the job offer probabilities underscore the importance of the labor market frictions. Table 4 presents the implied offer probabilities by whether the woman is younger or older than 62 . Women who do not work face very low probabilities of receiving either a full or part-time offer next period. In fact, women age 62 and over who do not work receive a full-time offer next period with only 1 to 2 percent probability. Thus, women who do

\footnotetext{
${ }^{42}$ The model was also estimated allowing for three types, but model fit did not improve above that of the model with two types. In addition, the model has been estimated with two and three types where types differ in their wage offer intercept, utility from leisure, and utility from caregiving, but fit did not improve in these cases either.

${ }^{43}$ The model was also estimated with nursing home utilization to see if nursing home use of mothers who cannot be left alone was generating the observed ordering of caregiving utilities (for example, $\alpha_{4}>\alpha_{5}$ ). Nursing home utilization occurred with some probability which depended on the mother's realized health state and last period's nursing home use. A (dis)utility parameter from caregiving while the mother is in a nursing home was introduced and estimated. The remaining caregiving utility parameter estimates were nearly identical to those presented here without nursing home use incorporated. Results from estimation of the model with nursing home use are available upon request.
} 
not work are likely to find it difficult to return to work in the future. Table 4 also shows that while moving between full and part-time work is easier than moving from non-work to employment, substantial frictions still exist. For example, the probability of receiving a parttime offer given a woman worked full-time last period ranges from 25 to 44 percent. This probability is larger for women who have reached the age of 62 , which captures the observed fact that many women transition from full to part-time work before retirement. These job offer probability estimates highlight important dynamic tradeoffs for caregivers. Those who leave work to provide care face low probabilities of receiving future offers, potentially leading to withdrawal from the labor force earlier than desired or expected. In addition, if a woman wishes to move from full to part-time work while providing care, such an option is not always available, and she may have to choose between combining full-time work with care responsibilities or not working. If she does work part-time while caregiving, she is not guaranteed to be able to move to full-time work in the future, but is more likely to do so if she is younger.

The wage offer parameters are reasonable and as expected. There is a wage penalty for not working in the previous period - a woman who did not work last period can expect a 13 percent lower wage offer than an otherwise similar woman who worked last period. These estimates also make clear static and dynamic tradeoffs between caregiving and work. Women who leave work to provide care forgo experience and the associated wage returns, and face a lower expected wage if they return to work. The estimates show that part-time jobs are associated with lower wage offers $\left(\beta_{7}=-0.252\right)$, which is important since both light and intensive caregivers are more likely to work part-time than non-caregivers. In addition, if a woman is considering decreasing her work hours while caregiving she must consider first that such an option may not be available since she may not receive a part-time offer, and second that the decrease in hours will lead to a lower expected wage. 


\subsection{Model Fit}

To examine the within-sample fit of the model, the parameter estimates are used to create a simulated sample consisting of 15 replicas of each sample individual's initial state variables. Table 5 reports the actual and simulated proportions of women working full-time, parttime, or not at all by their caregiving choice, conditional on the woman's mother being alive. The model predictions match the observed fact that light and intensive caregivers are more likely to be in part-time work than non-caregivers, and that intensive caregivers are less likely to be in full-time work than both non- and light caregivers. Table 6 reports the actual and simulated proportions of combined caregiving and work choices, conditional on the woman's mother being alive. Generally, the model fits these choice proportions well, but

slightly overstates non-work, regardless of caregiving choice. Table 7 compares the actual and simulated proportions of women lightly and intensively caregiving by the mother's health status. The model fits very well along these dimensions. In particular, it is able to match the fact that intensive caregiving is more frequent for mothers who are not healthy, and that caregiving is most prevalent when a mother has ADL needs or a memory problem. The model also fits accepted wages well, predicting an average accepted log wage of 2.626 compared to 2.669 in the actual data.

Importantly, the model should not only fit choice proportions, but also transitions in caregiving and work status. Table 8 shows observed caregiving transitions in the actual and simulated data. The model matches the fact that about two-thirds of caregivers continue caregiving (regardless of intensity) in the next period, conditional on the mother being alive. This prediction explicitly shows the persistence in caregiving generated by the model. The model also fits well the proportion of women who did not provide care in the previous period but caregive in the current period (regardless of intensity). Last, the model matches well the proportion of women who stop caregiving, due to either the death of the mother or the woman stopping care provision. Table 9 compares observed employment transitions in the actual and simulated data. The model matches the fact that transitions from non-work to 
full or part-time work are rare, and transitions from part-time to full-time work and vice versa occur with slightly higher probability.

\subsection{The Cost of Elder Parent Care}

The structural approach adopted in this paper allows for calculation of the cost of elder parent care, which reflects both the static and dynamic costs of caregiving. To determine this value, I implement a counterfactual scenario in which women who have unhealthy mothers must provide care. Specifically, the parameter estimates are used to create a simulated baseline sample consisting of 15 replicas of each sample individual's initial state space variables. The estimates are used to create another simulated sample of 15 replicas of each sample individual, but at age 55 or 56 (the average age of a caregiver) women who have an unhealthy mother must provide care. The removal of non-caregiving from the decision set comes as a surprise in that period, and she must make the best choice that involves providing care (of either intensity). ${ }^{44}$ I then calculate the lump-sum transfer needed to make a woman who was not providing care in the baseline indifferent between her choice in the caregiving counterfactual and her choice in the equivalent period in the baseline (i.e. the transfer needed to equalize the realized period value function in the caregiving counterfactual to the realized period value function in the baseline when she was not providing care). ${ }^{45}$

Figure 1 shows the distribution of transfer payments, excluding the top 90th percentile of transfers. The median transfer is $\$ 164,726$ per two-year period, which is about the cost of two years of nursing home care in a private room (MetLife, 2010b). ${ }^{46}$ Several previous studies, particularly in the gerontology literature, have also calculated a cost of informal

\footnotetext{
${ }^{44}$ Since women are surprised when they have to provide care and the same draws for the idiosyncratic shocks and unobserved utility arguments are used in the baseline and counterfactual scenarios, all pre-caregiving outcomes are unchanged, in particular prior work decisions.

${ }^{45}$ Women who were already caregiving at age 55 or 56 in the baseline are excluded from the analysis since there is no change in their behavior (i.e. their transfers are zero) and the measure of interest is the cost of moving from non-caregiving to caregiving.

${ }^{46}$ I have performed this counterfactual for a variety of ages (for example, forcing the woman to caregive at age 52 or 53), and the results are as expected - the costs of care provision are larger the younger a woman is when she must provide care. Intuitively, the earlier she provides care, the more time she potentially spends out of the labor market and the longer the caregiving episode could last.
} 
care. However, these studies typically calculate this value by multiplying the average hours of care provided by the average or median wage of a home health aide (the replacement wage approach), the minimum wage, or some average of the two (Ernst and Hay, 1994; Arno et al., 1999; Chappell et al., 2004; Feinberg et al., 2011). For example, Feinberg et al. (2011) estimate the cost of informal care based on caregivers providing an average of 18.4 hours of care per week at an average value of $\$ 11.16$ per hour, which amounts to $\$ 21,356$ over two years. This cost is substantially lower than the median cost I calculate above based on value function differences. Johnson and LoSasso (2000) perform a back of the envelope calculation and find the loss in annual work hours for female caregivers in the US translates on average into about $\$ 7,800$ in lost wages per year in 1994 dollars, or $\$ 22,663$ over two years in 2008 constant dollars, similar to that found in Feinberg et al. (2011). Ernst and Hay (1994) find the net cost of informal care for an Alzheimer's patient is $\$ 20,900$ per year in 1991 dollars, or $\$ 66,076$ over two years in 2008 dollars. This value is larger than those of the other studies since they estimate the weekly hours of informal care per week at 52.5, which is substantially higher than that found in most studies and the sample used in this paper. Their methodology based on 20 hours of care per week produces a value of $\$ 33,866$ over two years. The structural approach employed in this paper allows for calculating a cost of caregiving which incorporates the utility costs from initiating care, current and future foregone leisure and wages, parental health dynamics, and the option value of providing care. Except for current foregone wages, these features are not reflected in the approaches used in the above-mentioned studies, and it appears calculations based on the replacement wage approach or current foregone wages substantially underestimate the cost of elder parent care.

Interestingly, for women age 55 or 56 who were not caregiving in the baseline but provide care in the counterfactual and change their work choice in the counterfactual compared to the baseline, I find a median value of $\$ 21,220$ in current foregone labor income over a twoyear period. Thus, the estimated model delivers a cost of informal care that is consistent 
with that of the literature when adopting a current foregone wage approach. For these same women I find a median value of $\$ 51,780$ in lifetime foregone labor income. Thus, the model is capable of delivering a current foregone wage value that is nearly identical to that of the literature, but when estimating costs of caregiving by lifetime foregone labor income or value function differences, the costs are substantially larger, highlighting the importance of modeling caregiving and work decisions in an intertemporal framework.

\section{Policy Experiments}

One of the goals of this paper is to use the structural estimates to analyze how various government sponsored elder care policies affect a woman's caregiving and work decisions. For each policy I simulate a dataset using 15 replicas of each sample individual's initial state space variables and compare the results to those of the baseline dataset simulated without the policies. ${ }^{47}$ I consider a two-year unpaid leave, a two-year paid leave, and a caregiver allowance for intensive caregivers. ${ }^{48}$

\subsection{Unpaid Leave}

Currently in the US, the Family and Medical Leave Act (FMLA) of 1993 allows workers to take up to a 12-week unpaid leave to care for an ill family member and guarantees the worker will return to his/her job at the same wage. According to the US Department of Labor, caring for an ill parent was the next to least common reason (out of six) surveyed leave-takers utilized the FMLA, with only 10.6 percent of leave-takers using FMLA for that reason (Cantor et al., 2001). When asked about reasons for needing a leave (but not necessarily taking one), however, caring for an ill parent was the second most common reason. Some speculate this low take-up is due to the short duration and unpaid status of the leave. Motivated by the fact that an average caregiving spell lasts about four years (National Al-

\footnotetext{
${ }^{47}$ I use the same draws for the idiosyncratic shocks and unobserved utility arguments in the baseline and policy simulations.

${ }^{48}$ Throughout the analysis of the policy experiments, it is important to keep in mind the partial equilibrium setup of the model. The demand side of the labor market is considered completely exogenous. Thus, I assume employers do not adjust their behavior in response to the policies.
} 
liance for Caregiving and AARP, 2009), the first policy experiment involves an unpaid leave longer than the 12 weeks allowed under the FMLA. The policy experiment allows a woman to take a two-year unpaid leave from work to caregive intensively for her mother. Family work leaves of such length or longer are common in several European countries, such as Austria, Bulgaria, and Germany.

The policy is implemented as follows: Women who worked in the prior period (either full or part-time) have the option of caregiving intensively and not working during the current period with a guarantee that they will have a job offer for the type of job they left in the following period. There is also no wage penalty for not working during the leave. ${ }^{49}$ Thus, the leave alleviates a woman from combining work and intensive caregiving for a period, but she forgoes her labor income for that period. At the same time, the leave eliminates the uncertainty about returning to work since her job is held for her during the leave.

About 31 percent of women who are eligible take the unpaid leave, where eligible means the woman worked last period and is intensively caregiving in the current period. About 18 percent of women who intensively caregive are doing so while on leave. Columns 1 and 2 of Table 10 report the proportion of women providing intensive care by the mother's health status in the baseline simulation and in the unpaid leave simulation. The unpaid leave generates modest increases in intensive care provision.

There is evidence that the leave helps women to better maintain employment during and after a caregiving spell. Columns 1 and 2 of Table 11 report the employment status of women during and after intensive care provision in the baseline and unpaid leave simulations. The leave induces more work, especially full-time work, among these ever intensive caregivers compared to the baseline. Figure 2 shows the proportion of unpaid leave-takers in full and part-time work in the years before and after they take the leave compared to the corresponding periods in the baseline when the leave is not available. Women seem to take the unpaid leave at a time in the baseline when intensive care provision induces them to

\footnotetext{
${ }^{49}$ The leaves are aimed at women facing heavy caregiving burden and are not available to light caregivers.
} 
leave work, particularly full-time work. About 38 percent of those who take the leave left work in the equivalent period in the baseline and did not return. The unpaid leave, however, returns women to work and many of them continue working for several periods. There is a 44 (27) percent increase in the proportion of women in full-time (part-time) work in periods after the leave is taken compared to the corresponding periods in the baseline. Thus, it appears allowing women to take a leave to intensively caregive but removing the uncertainty about the availability of job offers after the leave encourages more full and part-time work for these women compared to when such a leave is unavailable. These results highlight the importance of labor market frictions for these caregivers.

\subsection{Paid Leave}

The second policy experiment is similar to the leave described above except the woman receives a lump-sum payment while on leave to intensively caregive, and the payment is linked to the health of the care recipient. Currently in the US, California and New Jersey have paid family leave programs, but caregivers can only take a leave for a maximum of 6 weeks, and payment is tied to the worker's wage. Payments to caregivers are very common in Europe and Canada, ${ }^{50}$ and payments to care recipients that are indexed to their health or level of need are also common. ${ }^{51}$ I consider a combination of these pre-existing policies in that the payment is provided directly to the caregiver while on leave, and the payment varies with the health of her mother.

I simulate the paid leave under two payment schemes. The first pays $\$ 6,600$ to women who intensively care for mothers with ADL needs or a memory problem and $\$ 13,200$ to women who intensively care for mothers who cannot be left alone. These amounts are loosely based on the monthly payments under Germany's Cash Allowance for Care extrapolated to a two-

\footnotetext{
${ }^{50}$ For example, the Swedish Temporary Care Leave pays a caregiver 80 percent of her normal labor income for a maximum leave of 60 days. Canada's Compassionate Care Benefit pays 55 percent of a caregiver's average earnings for up to six weeks while she cares for a terminally ill family member. Ireland's Carer's Benefit pays a maximum of 205 euros per week for up to 104 weeks to caregivers who leave work to "care for a person in need of full-time care and attention."

${ }^{51}$ For example, Austria's Cash Allowance for Care, Germany's Cash Allowance for Care, Luxembourg's Cash Allowance for Care, and the United Kingdom's Attendance Allowance.
} 
year period. The second payment system pays $\$ 18,250$ to women who intensively care for mothers with ADL needs or a memory problem and $\$ 36,500$ to women who intensively care for mothers who cannot be left alone. ${ }^{52}$ These amounts are based on the recently suspended CLASS Act, which aimed to create a voluntary government insurance benefit to provide long-term care support. Benefits were to be triggered once a participant needed ADL help or comparable assistance because of cognitive impairment. The law specified the average minimum benefit be $\$ 50$ per day with benefit amounts to be scaled based on the level of impairment. $^{53}$ I take a conservative approach and provide $\$ 25$ per day for two years to women caring for mothers with ADL needs or a memory problem and $\$ 50$ per day for two years to women caring for mothers who cannot be left alone.

Under the first payment scheme, 37 percent of eligible women take the paid leave, and not surprisingly even more (46 percent) take the leave under the second payment scheme. Table 10 shows that the paid leaves, particularly under the second payment scheme, generate somewhat larger increases in intensive care provision than the unpaid leave. Table 11 shows that the employment effects of the paid leave during and after intensive care provision are nearly identical to those of the unpaid leave. Figure 3 shows the proportion of paid leavetakers under the second payment scheme in full and part-time work in the years before and after they take the leave compared to the corresponding periods in the baseline. There is a 39 (25) percent increase in the proportion of women in full-time (part-time) work in periods after the paid leave is taken compared to the corresponding periods in the baseline. Again, these results are similar to those of the unpaid leave. Thus, the main differences between the unpaid and paid leaves are the take-up rate and subsequently how much intensive care provision is induced and government expenditure on the leave payments.

\footnotetext{
${ }^{52}$ Under both payments schemes, women who intensively care for healthy mothers can take a leave, but do not receive a payment. I make this assumption since the European and Canadian policies typically require the care recipient to have sufficient need for care.

${ }^{53}$ CLASS Act took effect in January 2011, but in October 2011, the Obama administration announced the program was suspended.
} 


\subsection{Caregiver Allowance}

The last policy experiment provides a payment to women who intensively caregive for their non-healthy mothers that is not linked to their employment status and may be received indefinitely. This policy experiment can inform about the labor market effects that would have occurred if the care recipient under the CLASS Act transferred the benefit payment in full to her caregiving daughter. The payment amounts are identical to those of the second paid leave payment scheme $\$ 18,250$ for intensively caregiving for a mother with ADL needs or a memory problem and $\$ 36,500$ for intensively caregiving for a mother who cannot be left alone. As seen in Table 10, the caregiver allowance generates the largest increase in intensive care provision among all the policies considered compared to the baseline. Two channels may be driving these results - first, the policy does not require the woman to leave work to receive the payment and second, the payment can be received indefinitely. I decompose this policy and simulate it under the leave rules, meaning a woman can receive the payment at most every other period, rather than indefinitely as long as she is providing intensive care. The decomposition shows the large increases in care provision are due mainly to the fact that the woman does not have to leave work to receive the payment. At the same time, this

policy discourages work among intensive caregivers due to the income effect of receiving this payment indefinitely. Table 11 shows that the caregiver allowance leads to a 2.8 percentage point increase in non-work among women who ever provide intensive care, which is mostly due to a reduction in full-time work.

\subsection{Retirement Effects of Policies}

Since a caregiver is typically in her fifties and sometimes early sixties, the policy experiments may have important retirement effects. Table 12 shows the employment status of women between the ages of 62 (the Social Security Early Entitlement Age) and 70 who ever provided intensive care in the baseline simulation, the work leave simulations, and the caregiver allowance simulation. Both the unpaid and paid leaves slightly increase the proportion of 
women 62 and over who work part-time compared to the baseline, and lead to moderate increases in full-time work. The caregiver allowance slightly decreases the percentage of women working full-time age 62 and over. Thus, it appears the work leaves reduce some early withdrawal from the labor force for women who have ever provided intensive care.

The retirement effects are stronger for women who took a leave at some point in the simulations. Table 13 compares the employment status of women 62 and over in the baseline and the policy simulations who ever took an unpaid or paid leave. The leaves decrease non-work by 15 to 16 percentage points compared to the baseline, which suggests the leaves are effective in preventing early retirement for many of these leave-takers. Given the average age of a leave-taker is between 57 and 58 , these results show that the one period removal of uncertainty regarding the ability of a caregiver to return to work has effects for several periods. In addition, the unpaid leave is just as effective as the paid leaves in encouraging work after age 62 , which is an important consideration for policy makers who may aim to protect the employment of caregivers while minimizing the government expenditure needed to do so.

\subsection{Welfare Comparison of Policies}

Using the estimates, I determine the value of the policy experiments for those who take them up. I calculate the lump-sum transfer needed to equalize the woman's realized period value function in the baseline (without any policies available) to her realized value function in the policy simulation in the period in which she takes up the policy being analyzed. ${ }^{54}$ Table 14 shows the median value of each policy experiment for all women who take up each particular policy, for the subset of women who take up the policy and were already intensively caregiving in the equivalent period in the baseline, and for women who were induced to provide intensive care by the policy. About 58 to 66 percent of the median value of the larger paid leave can be achieved with the unpaid leave, which suggests much of the benefit of the paid leaves comes

\footnotetext{
${ }^{54}$ The transfer is calculated for the period in which a woman takes a leave for the unpaid and paid leave experiments and during periods of intensive care provision for an unhealthy mother for the caregiver allowance experiment.
} 
from the guarantee the woman can return to work. In addition, the unpaid leave generates comparable welfare gains to the caregiver allowance which does not require a woman to leave work to receive the payment. These results further emphasize the importance of the labor market frictions for caregivers and the benefit of eliminating the uncertainty regarding the availability of full and part-time jobs.

Interesting patterns emerge when comparing the welfare gains for the subgroup of women who are induced to caregive by each policy. Those induced to intensively caregive for a nonhealthy mother by the smaller paid leave enjoy about $\$ 6,000$ more in welfare than those induced by the unpaid leave, which is less than the $\$ 6,600$ and $\$ 13,200$ leave payments. Those induced to intensively caregive for a non-healthy mother by the larger paid leave enjoy about $\$ 8,500$ more in welfare than those induced by the smaller paid leave, which is less than the $\$ 11,650$ and $\$ 23,300$ increase in leave payments. This can be explained in part by the differential take-up of the leaves. As the payments increase across the leaves, more women take them and are induced to intensively caregive. These marginal leave-takers necessarily value the leaves less than women who take all three leaves. The median value of the caregiver allowance for women induced to intensively caregive by this policy is only slightly larger than the $\$ 18,250$ payment and well below the $\$ 36,500$ payment. This value is also below the median value of the unpaid leave for those induced to intensively caregive by that policy, highlighting again the value of guaranteeing caregivers can return to work. These results have important implications for policy makers who may be concerned with balancing government expenditure with the welfare gains generated by the policies, particularly for women induced to care by the policies.

\section{Conclusion}

In this paper, I developed and estimated a dynamic discrete choice model of caregiving and work to study how elder parent care affects a woman's labor force participation and wages

over the short and long-term. In contrast to the previous literature, I model caregiving and work decisions in an explicitly intertemporal framework. Women make forward-looking 
decisions in a model which incorporates parental health uncertainty, human capital accumulation, and labor market frictions.

The model is estimated using data from the Health and Retirement Study by efficient method of moments. Based on the estimates, the model was shown to reasonably fit many aspects of the data. The estimates highlight various static and dynamic labor market tradeoffs faced by caregivers. Women who begin care provision are likely to continue to do so, especially if their parent is in poor health. In addition, women are more likely to provide intensive care when their parent is no longer healthy, and intensive caregivers are less likely to be working. The estimates also underscore the importance of labor market frictions. Women who do not work face low probabilities of receiving job offers in the future. As a result, if a woman leaves work while caregiving she may find it difficult to return. If she works part-time while caregiving, she is not guaranteed to be able to increase her hours in the future. The wage offer estimates show women who leave work forgo experience and the associated wage returns, and also face a lower expected wage if they return to work.

The estimates were used to calculate the cost of elder parent care. The median cost for a woman in her mid-fifties was found to be $\$ 164,726$ over two years, about the cost of two years of nursing home care, but about seven times larger than the values found in the previous literature. These previous values were calculated using the replacement wage approach or current foregone wages from providing care, and do not reflect the dynamic costs of care provision. Thus, calculations that ignore forward-looking behavior and the intertemporal nature of caregiving and work underestimate the cost of elder parent care.

The estimated model was used to analyze three counterfactual policy experiments: a twoyear unpaid leave, a two-year paid leave, and a caregiver allowance for intensive caregivers. The leaves generate modest increases in intensive caregiving and substantial decreases in non-work among women during and after intensive care provision, further highlighting the importance of the labor market frictions. There is also evidence that the leaves reduce early withdrawal from the labor force. The caregiver allowance on the other hand generates sub- 
stantial increases in intensive care provision but discourages work among those who ever intensively caregive. A comparison of the welfare gains generated by the policies shows that over half the value of the paid leave can be achieved with the unpaid leave. The welfare gains generated by the unpaid leave alone emphasize the value of guaranteeing a caregiver can return to work. The policy experiments illustrate the existence of two important tradeoffs faced by policy makers: (1) Protecting the employment of caregivers versus encouraging informal care provision by the family; and (2) Balancing government expenditure with the welfare gains generated by the policies.

\section{Appendix}

\section{A Utility Function}

The period utility function is given by:

$$
u_{t}=\ln \left(C_{t}\right)+\left(\alpha_{1, \ell}+\alpha_{2} a g e_{t}\right) \ln \left(L_{t}\right)+\alpha_{C G, H^{p}}+\alpha_{C G, C G_{-1}}+\alpha_{C G, s i s}+\nu_{t, E, C G}
$$

where

$$
\alpha_{1, \ell}=\alpha_{1,1} I(\text { type }=1)+\alpha_{1,2} I(\text { type }=2)
$$

and

$$
\begin{array}{r}
\alpha_{C G, H^{p}}=\alpha_{3} I\left(C G_{t}=1\right) I\left(H_{t}^{p}=\text { healthy }\right)+\alpha_{4} I\left(C G_{t}=1\right) I\left(H_{t}^{p}=A D L\right) \\
+\alpha_{5} I\left(C G_{t}=1\right) I\left(H_{t}^{p}=\text { alone }\right)+\alpha_{6} I\left(C G_{t}=2\right) I\left(H_{t}^{p}=\text { healthy }\right) \\
+\alpha_{7} I\left(C G_{t}=2\right) I\left(H_{t}^{p}=A D L\right)+\alpha_{8} I\left(C G_{t}=2\right) I\left(H_{t}^{p}=\text { alone }\right)
\end{array}
$$

and

$$
\begin{aligned}
\alpha_{C G, C G_{-1}}= & \alpha_{9} I\left(C G_{t} \neq 0\right) I\left(C G_{t-1}=0\right) I\left(H_{t}^{p}=\text { healthy }\right) \\
& +\alpha_{10} I\left(C G_{t} \neq 0\right) I\left(C G_{t-1}=0\right) I\left(H_{t}^{p}=A D L\right) \\
& +\alpha_{11} I\left(C G_{t} \neq 0\right) I\left(C G_{t-1}=0\right) I\left(H_{t}^{p}=\text { alone }\right)
\end{aligned}
$$


and

$$
\begin{aligned}
\alpha_{C G, \text { sis }}= & \alpha_{12} I\left(C G_{t} \neq 0\right) I\left(\text { sis }_{t}=1\right) I\left(H_{t}^{p}=\text { healthy }\right) \\
& +\alpha_{13} I\left(C G_{t} \neq 0\right) I\left(\text { sis }_{t}=1\right) I\left(H_{t}^{p}=A D L\right) \\
& +\alpha_{14} I\left(C G_{t} \neq 0\right) I\left(\text { sis }_{t}=1\right) I\left(H_{t}^{p}=\text { alone }\right) .
\end{aligned}
$$

The utility from not caregiving is normalized to zero across all health states.

\section{B Non-Labor Income}

Non-labor income is assumed to arrive from a degenerate distribution that depends on a woman's education, age, marital status, and whether her parent passed away since last period. Outside the structural model, I estimate the following regression:

$$
\begin{aligned}
\ln \left(y_{t}\right) & =\gamma_{0}+\gamma_{1} I\left(\text { educ }_{t}=2\right)+\gamma_{2} I\left(\text { educ }_{t}=3\right)+\gamma_{3} I\left(\text { mar }_{t}=1\right)+\gamma_{4} \text { age }_{t}+\gamma_{5} a g e_{t}^{2} \\
& +\gamma_{6} I\left(\text { age }_{t} \geq 62\right)+\gamma_{7} I\left(\text { mar }_{t}=1\right) I\left(\text { age }_{t} \geq 62\right)+\gamma_{8} I\left(\text { age }_{t} \geq 62\right) I\left(E_{t}=0\right) \\
& +\gamma_{9} I\left(H_{t}^{p}=\text { dead }\right) I\left(H_{t-1}^{p} \neq \text { dead }\right)
\end{aligned}
$$

where $y_{t}$ is non-labor income and $I\left(\right.$ mar $\left._{t}\right)$ is an indicator for whether the woman is married. Non-labor income depends on whether the woman is over the age of 62 since she can begin claiming Social Security retirement benefits at that age. The interaction term between marital status and achieving the Social Security Early Entitlement Age is meant to capture the drop in her spouse's labor earnings due to retirement as well as his potential receipt of Social Security benefits. Non-labor income depends on whether the woman's parent passed away since the prior period to capture potential inheritance receipt. Every period in the model, the woman receives non-labor income based on her characteristics as generated by equation 13. The estimates from the non-labor income regression are reported in Table 15.

\section{Unobserved Type Probability Function}

$$
\operatorname{Pr}(\text { type }=\ell)=\frac{\exp \left(\mu^{\ell} \boldsymbol{\Omega}\right)}{1+\sum_{m=2}^{2} \exp \left(\mu^{m} \boldsymbol{\Omega}\right)} \quad \ell \in\{1,2\},
$$


where

$$
\begin{aligned}
\mu^{\ell} \Omega= & \mu_{0}^{\ell}+\mu_{1}^{\ell} I\left(E_{-1}=P T\right)+\mu_{2}^{\ell} I\left(E_{-1}=F T\right)+\mu_{3}^{\ell} I\left(\operatorname{mar}_{0}=1\right)+\mu_{4}^{\ell} a e_{0} \\
& +\mu_{5}^{\ell} \ln w_{0}+\mu_{6}^{\ell} I\left(w_{0}=0\right)+\mu_{7}^{\ell} I\left(\text { asset }_{0}=2\right)+\mu_{8}^{\ell} I\left(\text { asset }_{0}=3\right),
\end{aligned}
$$

where $E_{-1}$ is the work choice of the woman preceding the period in which she enters the sample (period $t=0$ ). Recall that I do not use the 1992 survey wave data in the estimation, but the work choice of a woman observed in 1992 serves as her previous period's employment choice when she enters the estimation sample. If the woman enters the model with no wage (either because she did not work or the wage was not reported), she is assigned the average log wage observed in the data, and an indicator variable denotes that she entered without a wage. The woman's initial liquid assets are discretized into terciles. Coefficients for type 1 are normalized to zero.

\section{Auxiliary Models}

The following list consists of auxiliary models used in estimation:

1. Multinomial logits of non-work, part-time work, and full-time work on combinations of age, age squared, experience, experience squared, education indicators, indicators for last period's employment decision, an indicator for reaching age 62, a marital status indicator, and initial conditions.

2. Logits of caregiving (any intensity) versus not caregiving on combinations of parental health status indicators, an indicator for having a sister, and lagged caregiving for those with a mother alive.

3. Multinomial logits of no care, light care, and intensive care on combinations of age, parental health status indicators, an indicator for having a sister, lagged caregiving, and initial conditions for those with a mother alive.

4. Multinomial logits of the combined work-caregiving decision (9 choices total) on com- 
binations of experience, age, education indicators, lagged caregiving, indicators for last period's employment decision, an indicator for reaching age 62, a marital status indicator, an indicator for having a sister, and parental health status indicators for those with a mother alive.

5. Logit of transitions from not caregiving to caregiving (any intensity) on parental health status indicators for those with a mother alive.

6. Logit of transitions from caregiving (any intensity) to not caregiving on parental health status indicators for those with a mother alive.

7. Multinomial logits of transitions from non-employment to no work, part-time work, or full-time work; from part-time work to no work, part-time work, or full-time work; from full-time work to no work, part-time work, or full-time work on experience, education indicators, and an indicator for reaching age 62 .

8. Logits of transitions from non-full-time work to full-time work and from non-parttime work to part-time work on an indicator for not working last period, education indicators, and an indicator for reaching age 62 .

9. Regressions of $\log$ accepted wages on combinations of age, age squared, experience, experience squared, education indicators, indicators for last period's employment decision, and initial conditions.

\section{References}

Aguirregabiria, V. And P. Mira (2010): "Dynamic Discrete Choice Structural Models: A Survey," Journal of Econometrics, 156, 38-67.

Arno, P. S., C. Levine, And M. M. Memmott (1999): "The Economic Value of Informal Caregiving," Health Affairs, 18, 182-188. 
Bolin, K., B. Lindgren, And P. Lundborg (2008): "Your Next of Kin or Your Own Career? Caring and Working Among the 50+ of Europe," Journal of Health Economics, $27,718-738$.

Börsch-Supan, A., J. Gokhale, L. J. Kotlikoff, and J. N. Morris (1992): "The Provision of Time to the Elderly by Their Children," in Topics in the Economics of Aging, ed. by D. A. Wise, University of Chicago Press, 109-134.

Brown, M. (2006): "Informal Care and the Division of End-of-Life Transfers," The Journal of Human Resources, 41, 191-219.

_ (2007): "End-of-Life Transfers and the Decision to Care for a Parent," University of Wisconsin-Madison, Mimeo.

Byrne, D., M. S. Goeree, B. Hiedemann, and S. Stern (2009): "Formal Home Health Care, Informal Care, and Family Decision Making," International Economic Review, 50, 1205-1242.

Cantor, D., J. Waldfogel, J. Kerwin, M. McKinley Wright, K. Levin, And J. RAUCH (2001): "Balancing the Needs of Families and Employers: Family and Medical Leave Surveys, 2000 Update," Report, Department of Labor and Westat, Rockville, MD.

Carmichael, F. and S. Charles (1998): "The Labour Market Costs of Community Care," Journal of Health Economics, 17, 747-765.

_ (2003): "The Opportunity Costs of Informal Care: Does Gender Matter?" Journal of Health Economics, 22, 781-803.

Casado-Marín, D., P. García-Gómez, and A. López-Nicolás (2011): "Informal Care and Labour Force Participation Among Middle-Aged Women in Spain," SERIEs: Journal of the Spanish Economic Association, 2, 1-29. 
Chappell, N. L., B. Havens, M. J. Hollander, M. J. Ann, and C. McWilliam (2004): "Comparative Costs of Home Care and Residential Care," The Gerontologist, 44, $389-400$.

Checkovich, T. J. and S. Stern (2002): "Shared Caregiving Responsibilities of Adult Siblings with Elderly Parents," The Journal of Human Resourcs, 37, 441-478.

Crespo, L. And P. Mira (2010): "Caregiving to Elderly Parents and Employment Status of European Mature Women," CEMFI Working Paper No. 1007.

Eckstein, Z. And K. I. Wolpin (1999): "Why Youths Drop Out of High School: The Impact of Preferences Opportunities, and Abilities," Econometrica, 67, 1295-1330.

Engers, M. And S. Stern (2002): "Long-Term Care and Family Bargaining," International Economic Review, 43, 73-114.

Ernst, R. L. AND J. W. HAY (1994): "The US Economic and Social Costs of Alzheimer's Disease Revisited," American Journal of Public Health, 84, 1261-1264.

Ettner, S. L. (1995): "The Impact of 'Parent Care' on Female Labor Supply Decisions," Demography, 32, 63-80.

(1996): "The Opportunity Costs of Elder Care," The Journal of Human Resources, 31, 189-205.

Feinberg, L., S. C. Reinhard, A. Houser, and R. Choula (2011): "Valuing the Invaluable: 2011 Update The Growing Contributions and Costs of Family Caregiving," Insight on the Issues 51, AARP Public Policy Institute, Washington, DC.

Fevang, E., S. Kverndokk, And K. Roed (2012): "Labor Supply in the Terminal Stages of Lone Parents' Lives," Journal of Population Economics, 25, 1399-1422.

French, E. And J. B. Jones (2011): "The Effects of Health Insurance and Self-Insurance on Retirement Behavior," Econometrica, 79, 693-732. 
Gallant, A. R. and G. Tauchen (1996): "Which Moments to Match?" Econometric Theory, 12, 657-681.

Genton, M. G. And E. Rochetti (2003): "Robust Indirect Inference," Journal of the American Statistical Association, 98, 67-76.

Gourieroux, C., A. Monfort, And E. Renault (1993): "Indirect Inference," Journal of Applied Econometrics, 8, S85-S118.

Gustman, A. L. And T. L. Steinmeier (2005): "The Social Security Entitlement Age in a Structural Model of Retirement and Wealth," Journal of Public Economics, 89, 441-463.

Heitmueller, A. (2007): "The Chicken or the Egg? Endogeneity in Labour Market Participation of Informal Carers in England," Journal of Health Economics, 26, 536-559.

Heitmueller, A. And K. Inglis (2007): "The Earnings of Informal Carers: Wage Differentials and Opportunity Costs," Journal of Health Economics, 26, 821-841.

Heitmueller, A., P.-C. Michaud, And Z. Nazarov (2010): "A Dynamic Analysis of Informal Care and Employment in England," Labour Economics, 17, 455-465.

Hiedemann, B. And S. Stern (1999): "Strategic Play Among Family Members When Making Long-Term Care Decisions," Journal of Economic Behavior 83 Organization, 40, $29-57$.

Johnson, R. (2007): "The Burden of Caring for Frail Parents," Statement Before the Joint Economic Committee United States Congress.

Johnson, R. And A. LoSasso (2000): "The Trade-off Between Hours of Paid Employment and Time Assistance to Elderly Parents at Midlife," Urban Institute Working Paper.

Johnson, R. And J. M. Wiener (2006): "A Profile of Frail Older Americans and their Caregivers," The Retirement Project: Occasional Paper Number 8, The Urban Institute. 
Kaye, H. S., C. Harrington, and M. P. LaPlante (2010): "Long-Term Care: Who Gets It, Who Provides It, Who Pays, and How Much?" Health Affairs, 29, 11-21.

Keane, M. And A. A. Smith JR. (2003): "Generalized Indirect Inference for Discrete Choice Models," Yale Mimeo.

Keane, M. and K. Wolpin (1994): "The Solution and Estimation of Discrete Choice Dynamic Programming Models by Simulation and Interpolation: Monte Carlo Evidence," The Review of Economics and Statistics, 76, 648-672.

Knoef, M. And P. Kooreman (2011): "The Effects of Cooperation: A Structural Model of Siblings' Caregiving Interactions," Netpar Discussion Paper No. 05/2011-046.

MCGarRy, K. (1998): "Caring for the Elderly: The Role of Adult Children," in Inquiries in the Economics of Aging, ed. by D. A. Wise, University of Chicago Press, 133-166.

McGarry, K. And R. F. Schoeni (1997): "Transfer Behavior Within the Family: Results from the Asset and Health Dynamics Study," The Journals of Gerontology, 52B, 82-92.

MetLife (2009a): "Insights into the Oldest and Youngest Boomers," Report, MetLife Mature Market Institute, Westport, CT.

_ (2010b): "Market Survey of Long-Term Care Costs," Report, MetLife Mature Market Institute, Westport, CT.

Moscarola, F. C. (2010): "Informal Caregiving and Women's Work Choices: Lessons from the Netherlands," Labour: Review of Labour Economics and Industrial Relations, 24, $93-105$.

National Alliance for Caregiving and AARP (2009): "Caregiving in the US 2009," Report, National Alliance for Caregiving and AARP, Washington, DC.

Norton, E. And C. H. Van Houtven (2006): "Inter-vivos Transfers and Exchange," Southern Economic Journal, 73, 157-172. 
Pavalko, E. And J. Artis (1997): “Women's Caregiving and Paid Work: Causal Relationships in Late Midlife," Journal of Gerontology, 52B, S170-S179.

Rust, J., M. Buchinsky, And H. Benitez-Silva (2003): "Dynamic Structural Models of Retirement and Disability," SUNY Stony Brook Working Paper.

Spiess, C. K. AND U. SchneIder (2003): "Interactions Between Care-giving and Paid Work Hours among European Midlife Women," Ageing $\&$ Society, 23, 41-68.

Spillman, B. And L. Pezzin (2000): "Potential and Active Family Caregivers: Changing Networks and the 'Sandwich Generation'," Milbank Quarterly, 78, 347-374.

Szinovacz, M. E. And A. Davey (2008): "The Division of Parent Care Between Spouses," Ageing $\mathscr{6}$ Society, 28, 571-597.

TARTARI, M. (2006): "Divorce and the Cognitive Achievement of Children," Yale University, Mimeo.

Train, K. (2009): Discrete Choice Methods with Simulation, Cambridge University Press, 2nd edition ed.

VAN DeR KlaAuW, W. AND K. Wolpin (2008): "Social Security and the Retirement and Savings Behavior of Low-Income Households," Journal of Econometrics, 145, 21-42.

Van Houtven, C. H., N. B. Coe, and M. Skira (2013): "The Effect of Informal Care on Work and Wages," Journal of Health Economics, 32, 240-252.

Wolf, D. And B. Soldo (1994): "Married Women's Allocation of Time to Employment and Care of Elderly Parents," The Journal of Human Resources, 29, 1259-1276. 
Tables and Figures

Table 1: Descriptive Statistics

\begin{tabular}{lcccc}
\hline \hline & $\begin{array}{c}\text { Mother Not } \\
\text { Alive }\end{array}$ & $\begin{array}{c}\text { Non- } \\
\text { Caregiver }\end{array}$ & $\begin{array}{c}\text { Light } \\
\text { Caregiver }\end{array}$ & $\begin{array}{c}\text { Intensive } \\
\text { Caregiver }\end{array}$ \\
\hline $\begin{array}{l}\text { Employment } \\
\text { \% Not working }\end{array}$ & 59.35 & 41.69 & 43.55 & 52.54 \\
\% Working part-time & 16.38 & 17.47 & 19.46 & 19.15 \\
\% Working full-time & 24.27 & 40.85 & 36.99 & 28.31 \\
Mean accepted wage ${ }^{a}$ & $\$ 21.09$ & $\$ 20.74$ & $\$ 20.31$ & $\$ 18.16$ \\
\hline Mother's Health & & & & \\
\% Healthy & & 75.25 & 64.97 & 35.87 \\
\% ADL needs or memory problem & & 12.63 & 22.82 & 35.73 \\
\% Cannot be left alone & 12.12 & 12.20 & 28.39 \\
\hline Demographics and Family Structure & & & & \\
Mean age & 62.07 & 56.76 & 58.53 & 59.81 \\
\% Married & 77.99 & 81.90 & 80.61 & 74.93 \\
\% Has sister & 71.90 & 75.05 & 69.10 & 61.22 \\
\% Less than HS education & 21.81 & 20.48 & 14.48 & 14.27 \\
\% HS degree & 40.22 & 38.07 & 43.04 & 41.97 \\
\% Some college & 37.96 & 41.45 & 42.48 & 43.77 \\
$\quad$ Mean years of experience & 26.25 & 23.94 & 26.21 & 27.02 \\
\hline $\mathrm{N}$ & 7,125 & 7,187 & 3,032 & 722 \\
\hline Conditional on working & & & &
\end{tabular}

Table 2: Parental Health and Caregiving

\begin{tabular}{lccc}
\hline \hline & Healthy & ADL Needs & Alone \\
\hline \% Not caregiving & 70.81 & 48.87 & 60.23 \\
\% Lightly caregiving & 25.80 & 37.24 & 25.59 \\
\% Intensively caregiving & 3.39 & 13.89 & 14.18 \\
\hline $\mathrm{N}$ & 7,637 & 1,858 & 1,446 \\
\hline
\end{tabular}


Table 3: Main Parameter Estimates

\begin{tabular}{lccc}
\hline \hline Description & Parameter & Estimate & S.E. \\
\hline Utility Parameters & & & \\
Leisure (Type 1) intercept & $\alpha_{1,1}$ & 0.174 & 0.016 \\
Leisure (Type 2) intercept & $\alpha_{1,2}$ & 0.621 & 0.081 \\
Leisure age trend & $\alpha_{2}$ & 0.024 & 0.0004 \\
Light caregiving when $H^{p}=$ healthy & $\alpha_{3}$ & -0.248 & 0.026 \\
Light caregiving when $H^{p}=$ ADL & $\alpha_{4}$ & 0.317 & 0.051 \\
Light caregiving when $H^{p}=$ alone & $\alpha_{5}$ & -0.160 & 0.048 \\
Intensive caregiving when $H^{p}=$ healthy & $\alpha_{6}$ & -1.006 & 0.057 \\
Intensive caregiving when $H^{p}=$ ADL & $\alpha_{7}$ & 0.188 & 0.061 \\
Intensive caregiving when $H^{p}=$ alone & $\alpha_{8}$ & 0.094 & 0.090 \\
Initiating care when $H^{p}=$ healthy & $\alpha_{9}$ & -1.947 & 0.029 \\
Initiating care when $H^{p}=$ ADL & $\alpha_{10}$ & -1.826 & 0.045 \\
Initiating care when $H^{p}=$ alone & $\alpha_{11}$ & -1.555 & 0.081 \\
Caregiving and has a sister when $H^{p}=h e a l t h y$ & $\alpha_{12}$ & -0.155 & 0.017 \\
Caregiving and has a sister when $H^{p}=$ ADL & $\alpha_{13}$ & -0.209 & 0.052 \\
Caregiving and has a sister when $H^{p}=$ alone & $\alpha_{14}$ & -0.364 & 0.053 \\
\hline Log Wage Offer Parameters & & & \\
Intercept (Type 1) & $\beta_{0,1}$ & 0.353 & 0.003 \\
Intercept (Type 2) & $\beta_{0,2}$ & 0.377 & 0.021 \\
Age & $\beta_{1}$ & 0.058 & $9.28 \mathrm{E}-05$ \\
Age squared & $\beta_{2}$ & -0.0006 & $7.17 \mathrm{E}-07$ \\
Experience & $\beta_{3}$ & 0.046 & 0.0001 \\
Experience squared & $\beta_{4}$ & -0.0006 & $2.21 \mathrm{E}-06$ \\
HS degree & $\beta_{5}$ & 0.245 & 0.013 \\
Some college & $\beta_{6}$ & 0.654 & 0.011 \\
Part-time & $\beta_{7}$ & -0.252 & 0.025 \\
Did not work last period & $\lambda_{0}^{P T}$ & -1.102 & 0.046 \\
Variance of wage unobservable & $\lambda_{2}^{P T}$ & -1.576 & 0.082 \\
Part-Time Job Offer Logit Parameters & $\lambda_{3}^{P T}$ & 0.605 & 0.090 \\
Intercept & $\lambda_{4}^{P T}$ & 0.099 & 0.054 \\
Did not work last period & $\lambda_{0}^{F T}$ & -0.333 & 0.091 \\
Age 62+ & $\lambda_{1}^{F T}$ & -2.093 & 0.130 \\
HS degree & $\lambda_{2}^{F T}$ & -1.751 & 0.258 \\
Some college & 0.225 & 0.117 \\
Full-Time Job Offer Logit Parameters & 0.439 & 0.038 \\
Intercept & & \\
Did not work last period & & & \\
Age 62+ & & & \\
HS degree & & & \\
Some college & & & \\
\hline \hline
\end{tabular}




\begin{tabular}{lccc}
\hline \hline Description & Parameter & Estimate & S.E. \\
\hline Unobserved Type Probability Parameters & & & \\
Type 2: Intercept & $\mu_{0}^{2}$ & 0.051 & 0.086 \\
Type 2: Worked part-time before initial period & $\mu_{1}^{2}$ & 1.750 & 0.528 \\
Type 2: Worked full-time before initial period & $\mu_{2}^{2}$ & -1.339 & 0.085 \\
Type 2: Married at initial period & $\mu_{3}^{2}$ & -0.403 & 0.284 \\
Type 2: Age at initial period & $\mu_{4}^{2}$ & 0.009 & 0.002 \\
Type 2: Initial log wage & $\mu_{5}^{2}$ & 0.021 & 0.037 \\
Type 2: No initial log wage & $\mu_{6}^{2}$ & 1.148 & 0.392 \\
Type 2: Initial asset tercile 2 & $\mu_{7}^{2}$ & -0.675 & 0.162 \\
Type 2: Initial asset tercile 3 & $\mu_{8}^{2}$ & 0.689 & 0.208 \\
\hline Other Parameters & \multicolumn{3}{|c}{} \\
Discount factor (not estimated) & $\beta$ & & \\
& & &
\end{tabular}

Covariance Matrix for Unobserved Utility Arguments

This matrix governs the unobserved utility from each joint caregiving and work choice when women have a mother alive: 


\begin{tabular}{|c|c|c|c|c|c|c|c|c|c|}
\hline & $\nu_{0,0}$ & $\nu_{0,1}$ & $\nu_{0,2}$ & $\nu_{P T, 0}$ & $\nu_{P T, 1}$ & $\nu_{P T, 2}$ & $\nu_{F T, 0}$ & $\nu_{F T, 1}$ & $\nu_{F T, 2}$ \\
\hline$\nu_{0,0}$ & 1.000 & & & & & & & & \\
\hline \multirow[t]{2}{*}{$\nu_{0,1}$} & -0.627 & 1.789 & & & & & & & \\
\hline & $(0.059)$ & $(0.073)$ & & & & & & & \\
\hline \multirow[t]{2}{*}{$\nu_{0,2}$} & -0.263 & 0.074 & 1.262 & & & & & & \\
\hline & $(0.088)$ & $(0.147)$ & $(0.044)$ & & & & & & \\
\hline \multirow[t]{2}{*}{$\nu_{P T, 0}$} & -0.073 & 0.00 & 0.00 & 0.498 & & & & & \\
\hline & $(0.094)$ & & & $(0.030)$ & & & & & \\
\hline \multirow[t]{2}{*}{$\nu_{P T, 1}$} & 0.00 & 0.00 & 0.00 & 0.223 & 2.499 & & & & \\
\hline & & & & $(0.068)$ & $(0.153)$ & & & & \\
\hline \multirow[t]{2}{*}{$\nu_{P T, 2}$} & 0.00 & 0.00 & 0.00 & 0.237 & 1.279 & 2.066 & & & \\
\hline & & & & $(0.186)$ & $(0.080)$ & $(0.120)$ & & & \\
\hline \multirow[t]{2}{*}{$\nu_{F T, 0}$} & 0.091 & 0.00 & 0.00 & 0.00 & 0.00 & 0.00 & 1.097 & & \\
\hline & $(0.088)$ & & & & & & $(0.095)$ & & \\
\hline \multirow[t]{2}{*}{$\nu_{F T, 1}$} & 0.00 & 0.00 & 0.00 & 0.00 & 0.00 & 0.00 & -0.818 & 1.615 & \\
\hline & & & & & & & $(0.046)$ & $(0.096)$ & \\
\hline \multirow[t]{2}{*}{$\nu_{F T, 2}$} & 0.00 & 0.00 & 0.00 & 0.00 & 0.00 & 0.00 & -0.304 & -0.342 & 1.109 \\
\hline & & & & & & & $(0.083)$ & $(0.084)$ & $(0.065)$ \\
\hline
\end{tabular}

The variance of the unobserved utility from not working and not caregiving has been normalized to one. Most covariances of unobserved utility across work choices are set equal to zero since not all terms of the covariance matrix can be identified (Train, 2009).

This matrix governs the unobserved utility from each work choice when women do not 
have a mother alive:

\begin{tabular}{cccc} 
& $\nu_{0}$ & $\nu_{P T}$ & $\nu_{F T}$ \\
\hline$\nu_{0}$ & 1.000 & & \\
$\nu_{P T}$ & 0.049 & 0.188 & \\
& $(0.062)$ & $(0.074)$ & \\
& & & \\
$\nu_{F T}$ & -0.737 & 0.00 & 0.908 \\
& $(0.066)$ & & $(0.135)$
\end{tabular}

The variance of the unobserved utility from not working has been normalized to one.

Table 4: Offer Probabilities

\begin{tabular}{|c|c|c|c|}
\hline & & Younger than 62 & 62 and Older \\
\hline$\%$ PT offer & $\mathrm{E}_{t-1}=0$ & $6-8$ & $11-14$ \\
\hline$\%$ FT offer & $\mathrm{E}_{t-1}=0$ & $8-10$ & $1-2$ \\
\hline \% PT offer & $\mathrm{E}_{t-1}=\mathrm{FT}$ & $25-30$ & $38-44$ \\
\hline$\%$ FT offer & $\mathrm{E}_{t-1}=\mathrm{PT}$ & $42-48$ & $11-14$ \\
\hline
\end{tabular}

There are a range of offers in each cell since offers vary with the woman's education.

Table 5: Employment Status by Caregiving Type

\begin{tabular}{lcccccc}
\hline \hline & \multicolumn{2}{c}{ Non-Caregiver } & \multicolumn{2}{c}{ Light Caregiver } & \multicolumn{2}{c}{ Intensive Caregiver } \\
\hline & Actual & Simulated & Actual & Simulated & Actual & Simulated \\
\hline \% Not working & 41.69 & 46.61 & 43.55 & 47.21 & 52.54 & 53.93 \\
\% Working part-time & 17.47 & 16.64 & 19.46 & 18.87 & 19.15 & 17.90 \\
\% Working full-time & 40.85 & 36.75 & 36.99 & 33.92 & 28.31 & 28.17 \\
\hline
\end{tabular}


Table 6: Joint Caregiving and Work Choices

\begin{tabular}{lcc}
\hline \hline & Actual & Simulated \\
\hline \% Not working, not caregiving & 27.42 & 29.65 \\
\% Not working, light caregiving & 12.05 & 13.89 \\
\% Not working, intensive caregiving & 3.44 & 3.76 \\
\% Working part-time, not caregiving & 11.49 & 10.59 \\
\% Working part-time, light caregiving & 5.38 & 5.55 \\
\% Working part-time, intensive caregiving & 1.25 & 1.25 \\
\% Working full-time, not caregiving & 26.87 & 23.37 \\
\% Working full-time, light caregiving & 10.24 & 9.98 \\
\% Working full-time, intensive caregiving & 1.85 & 1.96 \\
\hline
\end{tabular}

Table 7: Caregiving by Mother's Health Status

\begin{tabular}{lcccccc}
\hline \hline & \multicolumn{2}{c}{ Healthy } & \multicolumn{2}{c}{ ADL Needs } & \multicolumn{2}{c}{ Alone } \\
\hline & Actual & Simulated & Actual & Simulated & Actual & Simulated \\
\hline \% Lightly caregiving & 25.80 & 27.95 & 37.24 & 36.75 & 25.59 & 25.61 \\
\% Intensively caregiving & 3.39 & 3.61 & 13.89 & 13.93 & 14.18 & 14.64 \\
\hline
\end{tabular}

Table 8: Caregiving Transitions

\begin{tabular}{lcc}
\hline \hline & Actual & Simulated \\
\hline \% Caregivers who care again next period & 68.00 & 67.18 \\
\% Transitioning from non-caregiving to caregiving & 22.40 & 22.63 \\
\% Transitioning from caregiving to non-caregiving & 42.43 & 44.04 \\
\hline
\end{tabular}

Table 9: Employment Transitions

\begin{tabular}{l|c|c|c}
\hline \hline & $\mathbf{E}_{\mathbf{t}}=\mathbf{0}$ & $\mathbf{E}_{\mathbf{t}}=\mathbf{P T}$ & $\mathbf{E}_{\mathbf{t}}=\mathbf{F T}$ \\
\hline \multirow{2}{*}{$\mathbf{E}_{\mathbf{t}-\mathbf{1}}=\mathbf{0}$} & $89.48(\mathrm{~A})$ & $6.64(\mathrm{~A})$ & $3.87(\mathrm{~A})$ \\
& $90.34(\mathrm{~S})$ & $6.32(\mathrm{~S})$ & $3.34(\mathrm{~S})$ \\
\hline \multirow{2}{*}{$\mathbf{E}_{\mathbf{t}-\mathbf{1}}=\mathbf{P T}$} & $24.66(\mathrm{~A})$ & $58.60(\mathrm{~A})$ & $16.75(\mathrm{~A})$ \\
& $24.84(\mathrm{~S})$ & $59.13(\mathrm{~S})$ & $16.03(\mathrm{~S})$ \\
\hline \multirow{2}{*}{$\mathbf{E}_{\mathbf{t}-\mathbf{1}}=\mathbf{F T}$} & $13.91(\mathrm{~A})$ & $10.64(\mathrm{~A})$ & $75.45(\mathrm{~A})$ \\
& $16.91(\mathrm{~S})$ & $9.82(\mathrm{~S})$ & $73.27(\mathrm{~S})$ \\
\hline
\end{tabular}

The relative frequency of each cell within its row is reported.

(A): Actual (S): Simulated

Table 10: Intensive Care Provision by Mother's Health

\begin{tabular}{lccccc}
\hline \hline & & Unpaid & Paid & Paid & Caregiver \\
& Baseline & Leave & Leave I & Leave II & Allowance \\
\hline \% Intensively caregiving $\mid H^{p}=$ healthy & 3.61 & 4.11 & 4.12 & 4.14 & 3.75 \\
\% Intensively caregiving $\mid H^{p}=$ ADL & 13.93 & 15.53 & 16.24 & 17.33 & 21.30 \\
\% Intensively caregiving $\mid H^{p}=$ alone & 14.64 & 16.42 & 17.97 & 20.34 & 28.20 \\
\hline
\end{tabular}


Table 11: Employment of Women Who Ever Provide Intensive Care

\begin{tabular}{lccccc}
\hline \hline & & Unpaid & Paid & Paid & Caregiver \\
& Baseline & Leave & Leave I & Leave II & Allowance \\
\hline \% Not working & 59.45 & 53.83 & 52.81 & 51.55 & 62.24 \\
\% Working part-time & 16.40 & 17.36 & 17.71 & 18.02 & 16.15 \\
\% Working full-time & 24.15 & 28.81 & 29.48 & 30.43 & 21.61 \\
\hline
\end{tabular}

Employment status shown for women in periods during and after intensive care provision.

Table 12: Employment of Women 62 and Over Who Ever Provide Intensive Care

\begin{tabular}{lccccc}
\hline \hline & & Unpaid & Paid & Paid & Caregiver \\
& Baseline & Leave & Leave I & Leave II & Allowance \\
\hline \% Not working & 69.50 & 64.69 & 63.34 & 61.85 & 71.56 \\
\% Working part-time & 15.75 & 16.80 & 17.23 & 17.64 & 15.42 \\
\% Working full-time & 14.75 & 18.51 & 19.43 & 20.50 & 13.02 \\
\hline
\end{tabular}

Employment status shown for women in periods during and after intensive care provision.

Table 13: Employment Comparison of Women 62 and Over Who Ever Took a Leave

\begin{tabular}{lcccccc}
\hline \hline & \multicolumn{2}{c}{$\begin{array}{c}\text { Unpaid Leave } \\
\text { Takers }\end{array}$} & \multicolumn{2}{c}{$\begin{array}{c}\text { Paid Leave I } \\
\text { Takers }\end{array}$} & \multicolumn{2}{c}{$\begin{array}{c}\text { Paid Leave II } \\
\text { Takers }\end{array}$} \\
\hline & Baseline & Policy & Baseline & Policy & Baseline & Policy \\
\hline \% Not working & 65.06 & 49.24 & 62.25 & 46.86 & 60.33 & 45.15 \\
\% Working part-time & 15.84 & 20.00 & 17.09 & 21.33 & 17.64 & 21.99 \\
\% Working full-time & 19.10 & 30.76 & 20.66 & 31.81 & 22.02 & 32.86 \\
\hline
\end{tabular}

Table 14: Welfare Comparison of Policy Experiments

\begin{tabular}{lcccccc}
\hline \hline & $\begin{array}{c}\text { Unpaid } \\
\text { Leave }\end{array}$ & $\begin{array}{c}\text { Paid } \\
\text { Leave I }^{a}\end{array}$ & $\begin{array}{c}\text { Paid } \\
\text { Leave I }^{b}\end{array}$ & $\begin{array}{c}\text { Paid } \\
\text { Leave II }^{a}\end{array}$ & $\begin{array}{c}\text { Paid } \\
\text { Leave II }^{b}\end{array}$ & $\begin{array}{c}\text { Caregiver } \\
\text { Allowance }\end{array}$ \\
\hline Median value & $\$ 27,880$ & $\$ 32,163$ & $\$ 36,486$ & $\$ 41,900$ & $\$ 47,867$ & $\$ 31,114$ \\
Always caregivers & $\$ 26,863$ & $\$ 34,395$ & $\$ 38,325$ & $\$ 49,372$ & $\$ 57,837$ & $\$ 37,185$ \\
Induced caregivers & $\$ 28,181$ & $\$ 30,973$ & $\$ 34,017$ & $\$ 38,571$ & $\$ 42,567$ & $\$ 19,944$ \\
\hline
\end{tabular}

${ }^{a}$ Includes those on leave caring for a healthy parent, but not receiving a payment.

${ }^{b}$ Excludes those on leave caring for a healthy parent.

Always caregivers are those who were intensively caregiving in the equivalent period in the baseline.

Induced caregivers are those who were not intensively caregiving in the equivalent period in the baseline. 
Table 15: Non-Labor Income Estimates

\begin{tabular}{lccc}
\hline \hline Description & Parameter & Estimate & S.E. \\
\hline Intercept & $\gamma_{0}$ & 16.440 & 1.005 \\
HS degree & $\gamma_{1}$ & 0.285 & 0.034 \\
Some college & $\gamma_{2}$ & 0.597 & 0.035 \\
Married & $\gamma_{3}$ & 1.398 & 0.044 \\
Age & $\gamma_{4}$ & -0.276 & 0.035 \\
Age squared & $\gamma_{5}$ & 0.002 & 0.0003 \\
Age 62+ & $\gamma_{6}$ & 0.801 & 0.070 \\
Married and age 62+ & $\gamma_{7}$ & -0.958 & 0.060 \\
Age 62+ and not working & $\gamma_{8}$ & 0.074 & 0.041 \\
Mother passed away & $\gamma_{9}$ & 0.095 & 0.042 \\
\hline
\end{tabular}

Figure 1: Distribution of the Cost of Caregiving for Women Age 55-56

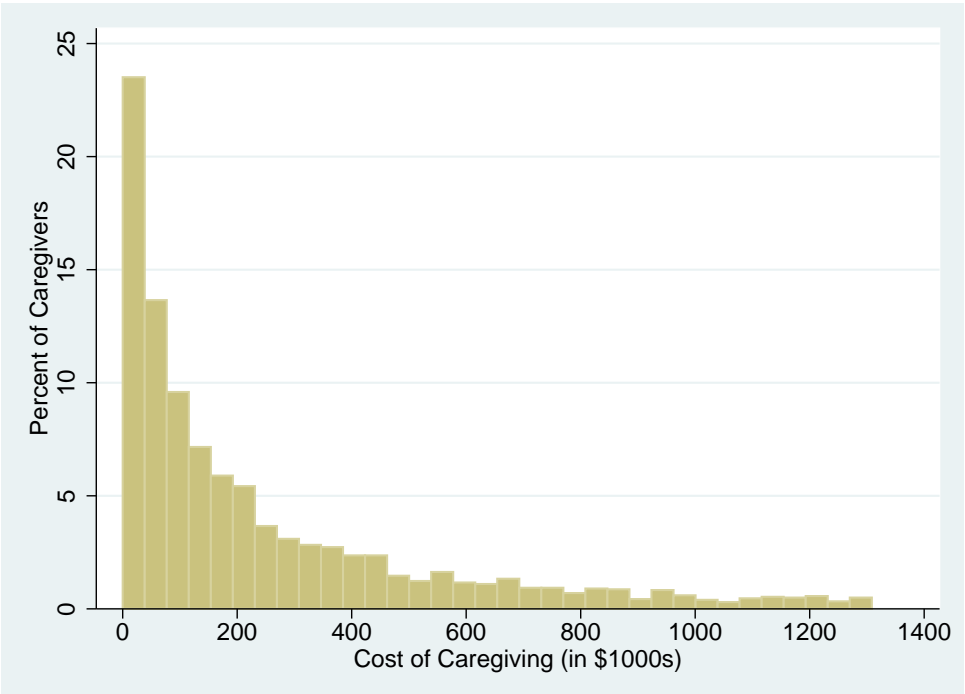


Figure 2: Unpaid Leave Results

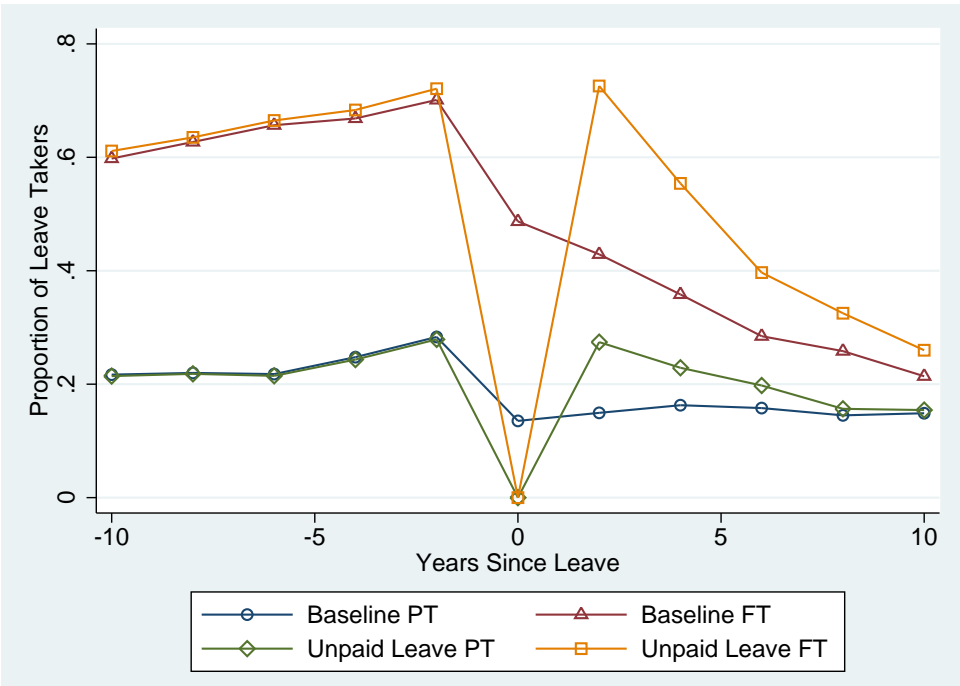

Figure 3: Paid Leave Results

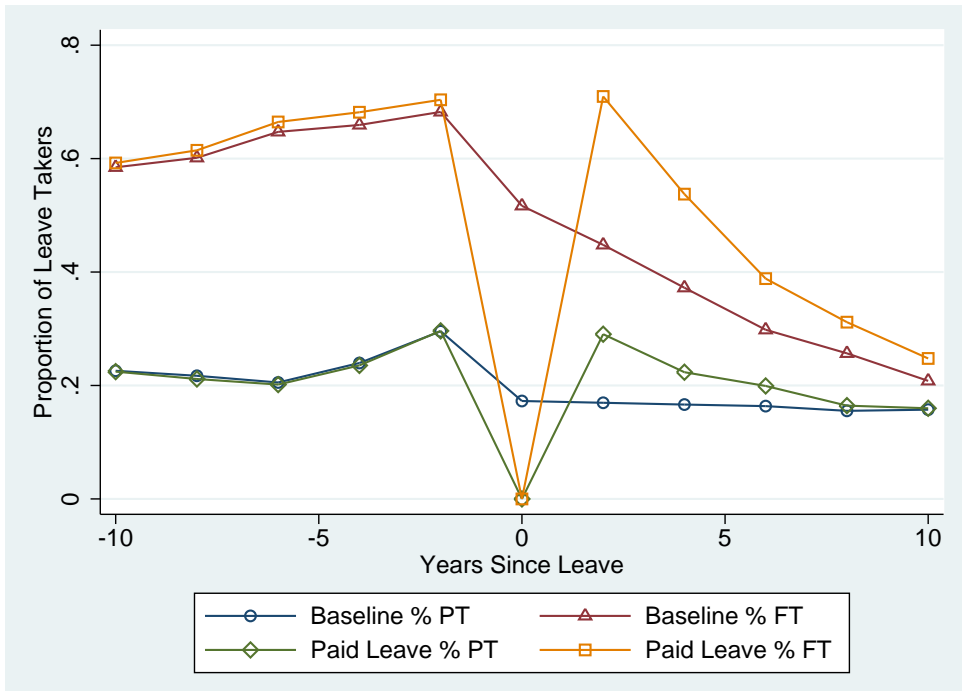

